Paula Simone Saia

\title{
SISTEMA CERATOMÉTRICO DE APOIO A SUTURAS NA CÓRNEA
}

Dissertação apresentada à

Escola de Engenharia de São Carlos da Universidade de São Paulo, como parte dos requisitos para a obtenção do Título de Mestre em Engenharia Elétrica.

Orientadora: Profa. Dra. Liliane Ventura

São Carlos 
AUTORIZO A REPRODUÇÃO E DIVULGAÇÃO TOTAL OU PARCIAL DESTE TRABALHO, POR QUALQUER MEIO CONVENCIONAL OU ELETRÔNICO, PARA FINS DE ESTUDO E PESQUISA, DESDE QUE CITADA A FONTE.

Ficha catalográfica preparada pela Seção de Tratamento da Informação do Serviço de Biblioteca - EESC/USP

Saia, Paula Simone
Sistema ceratométrico de apoio a suturas na córnea /
Paula Simone Saia i orientadora Liliane Ventura. -- São
Carlos, 2007.
Dissertação (Mestrado) - Programa de Pós-Graduação em
Engenharia e Área de Concentração em Engenharia Elétrica.
-- Escola de Engenharia de São Carlos da Universidade de
São Paulo.
1. Ceratometria intra-cirúrgica. 2. Sutura corneana.
3. Córnea. I. Título.


Às pessoas que se dedicam e querem construir um País melhor para nossos filhos. 


\section{AGRADECIMENTOS}

Agradeço,

À Profa. Liliane pela realização desta dissertação;

Ao Prof. Jean-Jaques De Groote pelo programa desenvolvido;

Ao Gunter e ao César, amigos integrantes do Laboratório de Instrumentação Oftálmica - EESC/USP, pela parte eletrônica realizada;

Ao Rui Bertho, pela compreensão e prontidão nas confecções das peças mecânicas;

Ao Prof. Sidney Júlio de Faria e Sousa pelas críticas e discussões construtivas e por permitir acesso ao ambulatório cirúrgico;

Ao Dr. Erik Alexandro Pedro, por ceder o topógrafo corneano manual para realização das medidas;

À pós-graduação por todo o suporte neste período;

Aos funcionários do Departamento de Engenharia Elétrica da Escola de Engenharia de São Carlos - USP pelo suporte sempre presente;

Ao Instituto de Física de São Carlos - USP pelo corte e polimento dos capilares de vidro;

À CAPES pelo suporte financeiro. 
Um sistema para auxílio à cirurgias oftálmicas foi desenvolvido com o objetivo de se minimizar o astigmatismo induzido devido ao formato irregular da córnea pelo ato de sutura. O sistema projeta 48 pontos de luz no filme lacrimal da córnea, provenientes de LEDs, dispostos num diâmetro precisamente circular. O deslocamento, a dimensão e a deformação da imagem refletida destes pontos luminosos são analisados proporcionando a ceratometria e a circularidade da sutura. O intervalo de medidas do sistema é de 32D - 55D (astigmatismos até 23D podem ser medidos) e um sistema para calibração do sistema foi projetado para manter o sistema calibrado. Esferas de aço de precisão foram submetidas ao sistema e uma correlação de $99 \%$ entre as medidas obtidas e os valores dos fabricantes foi obtida. O sistema foi testado em 13 voluntários para avaliação de sua aplicabilidade clínica e comparado a um ceratômetro comercial Topcon OM-4. Os fatores de correlação entre o sistema desenvolvido e o Topcon OM-4, para o astigmatismo, foi de $r^{2}=0,92$, e em relação ao eixo, o fator é $r^{2}=0,99$. O sistema indica que o cirurgião deve obter uma circularidade $\geq 98 \%$ para que astigmatismos acima de $3 D$ não sejam induzidos na sutura.

Palavras-chave: ceratometria intra-cirúrgica, sutura corneana, córnea 


\section{ABSTRACT}

A system for ophthalmic surgery support has been developed in order to minimize the residual astigmatism due to the induced irregular shape of the cornea by corneal suture. The system projects 48 light spots, from LEDs, displayed in a precise circle at the lachrymal film of the examined cornea. The displacement, the size and deformation of the reflected image of these light spots are analyzed providing the keratometry and the circularity of the suture. Measurements in the range of $32 D-55 D$ (up to $23 D$ of astigmatism are possible to be obtained) and a self-calibration system has been designed in order to keep the system calibrated. Steel precision spheres have been submitted to the system and the results show $99 \%$ of correlation with the fabricant's nominal values. The system has been tested in 13 persons in order to evaluate its clinical applicability and has been compared to a commercial keratometer Topcon OM-4. The correlation factors are 0,92 for the astigmatism and 0.99 for the associated axis. The system indicates that the surgeon should achieve circularity $\geq 98 \%$ in order to do not induce astigmatisms over 3D.

Key-words: surgical keratomery, corneal suture, cornea 


\section{LISTA DE FIGURAS}

Figura 1.1: (a) O olho humano - acessado em 06/10/2007 -

(http://www.vision.ime.usp.br/ ronaldo/mac0417-03/aula_02/BIO2_329.jpg -);(b) As camadas da córnea (http://www.uniteforsight.org/course/image/cornea.jpg acessado em 06/10/2007) ... 4

Figura 1.2: (a) Microscópio cirúrgico da marca Zeiss; (b) Detalhe do microscópio com câmera de vídeo acoplada (www.zeiss.com - acessado em $06 / 10 / 2007) \ldots 10$

Figura 2.1: Representação esquemática do astigmatismo (http://www.sac.org.br/APR_DO.htm, acessada em 10/09/2007) ... 12

Figura 2.2: Classificação do astigmatismo regular: (a) hipermétrope composto; (b) hipermétrope simples; (c) misto; (d) míope simples; (e) míope composto; (f) sem astigmatismo ... 14

Figura 2.3. Representação do Círculo de Menor Confusão ... 16 
Figura 2.4: Representação de superfícies: (a) esféricas; (b) toroidais; (c) cilíndrica positiva (ou convexa); (d) cilíndrica negativa (ou côncava) ... 18

Figura 2.5: (a) Anel de Flieringa; (b) Visão do paciente do Ceratômetro de Troutman $\ldots 22$

Figura 3.1: Formação de imagens por espelhos convexos, com tamanho do objeto constante e de imagem variável [HECHT, E.; 1990] ... 25

Figura 3.2: Formação de imagens por espelhos convexos, com tamanho da imagem constante e tamanho de objeto variável ... 26

Figura 3.3: Diagrama esquemático do princípio da ceratometria ... 28

Figura 3.4: Ceratômetro cirúrgico quantitativo de C. M. Terry ... 33

Figura 4.1: (a) Dispositivo; (b) mira observada pelo paciente; (c) imagem refletida em uma esfera de aço; (d) imagem refletida do olho do paciente ... 35

Figura 4.2: Tela de interface do programa ceratométrico desenvolvido ... 35

Figura 4.3: Desenho esquemático do microscópio da Carl Zeiss Medtec (desenho acessado em 21/09/2007 em http://www.meditec.zeiss.com) com 
indicações dos acessórios a serem acoplados para o sistema de apoio à cirurgia ... 36

Figura 4.4: (a) Anel acoplado ao adaptador de vídeo da APRAMED $^{\circledR}$ (b). Foto frontal do anel de capilares de vidro e mira de alinhamento ótico ... 38

Figura 4.5: (a) Imagem do alvo projetada numa córnea de voluntário, apresentada pelo sistema da figura $4.2 \ldots 39$

Figura 4.6: Projeto do invólucro de nylon preto que aloja o anel com 36 LEDs ... 40

Figura 4.7: Fotos: (a) anel de PVC preto, (b) placa do circuito impresso... 41

Figura 4.8: Anel composto por 36 LEDs brancos do tipo "luz do dia" ... 42

Figura 4.9: (a) Sistema para apoio cirúrgico; (b) Simulação da medida em campo cirúrgico ... 43

Figura 4.10: Imagem refletida da projeção do anel em: (a) esfera de aço inox; (b) olho de uma voluntária do Laboratório de Instrumentação Oftálmica EESC/USP ... 44 
Figura 5.1: Representação da elipse determinada no algoritmo, melhor ajustada às imagens dos LEDs ... 48

Figura 5.2: Seções cônicas com excentricidades diferentes ... 51

Figura 5.3: Tela de apresentação durante a focalização da mira na córnea do paciente ... 53

Figura 5.4: Dispositivo de calibração do sistema ... 54

Figura 5.5: Telas de Calibração do sistema: (a) Calibração em andamento; (b) sistema calibrado ... 56

Figura 5.6: Tela dos resultados apresentados: imagem capturada, ceratometria e circularidade ...57

Figura 6.1: Gráfico dos raios de curvatura medidos das 21 esferas em nosso sistema e comparadas ao valores fornecidos pelo fabricante $\ldots 59$

Figura 6.2: Foto do dispositivo em cunha utilizado para deformar as lentes de contato, sobre um sistema que é rotacionado manualmente, a cada $1^{\circ} \ldots 60$ 
Figura 6.3: Gráfico dos poderes de refração, para a lente A, medidos em nosso sistema e no ceratômetro Topcon OM-4, onde cada ponto corresponde à variação de $1^{\circ} \ldots 65$

Figura 6.4: Gráfico para a lente A dos valores medidos em nosso sistema do ângulo obtido, quando o dispositivo mecânico é rotacionado a cada $1^{\circ} \ldots 66$

Figura 6.5: Gráficos de correlação dos dois sistemas para o: (a) astigmatismo e; (b) eixo associado ... 70 


\section{LISTA DE TABELAS}

Tabela 6.1: Repetibilidade de Medidas dos Raios de Curvatura de Esferas de Precisão ... 59

Tabela 6.2: Deformações realizadas à $90^{\circ}$ para três lentes de contato e os resultados obtidos pelo ceratômetroTopcon OM-4 e por nosso sistema ... 61

Tabela 6.3: Dados obtidos, a cada $1^{\circ}$ da lente A, no ceratômetro Topcon OM-4 e no nosso sistema, bem como o valor teórico esperado ... 62

Tabela 6.4: medidas dos voluntários em relação ao poder de refração do astigmatismo e ao eixo associado do nosso sistema comparados ao ceratômetro Topcon OM-4 ... 69 


\section{SUMÁRIO}

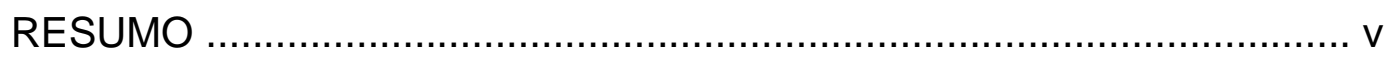

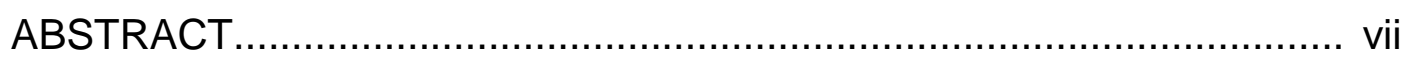

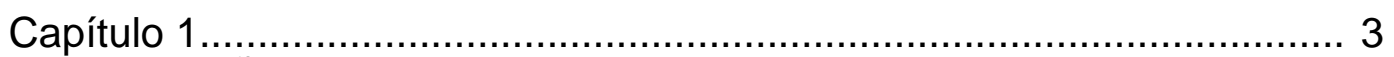

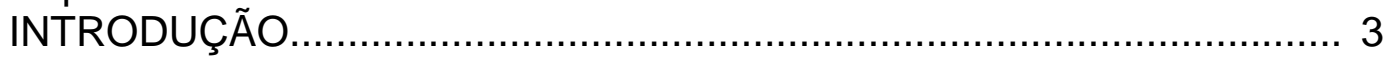

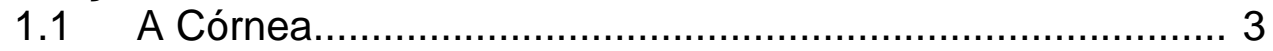

1.2 O Ceratômetro........................................................... 5

1.3 O Microscópio Cirúrgico.................................................... 9

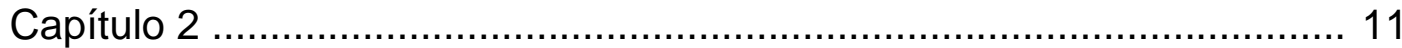

O ASTIGMATISMO E OS SISTEMAS INTRA-CIRÚRGICOS................. 11

2.1 O Astigmatismo e suas Correções..................................... 11

2.2 Tipos De Astigmatismo....................................................... 12

2.2.1 Astigmatismo Regular............................................ 13

2.3 O Círculo de Menor Confusão............................................... 15

2.4 A Correção Óptica do Astigmatismo......................................16

2.5 O Astigmatismo e o Transplante de Córnea..........................19

2.5.1 Sistemas Existentes para Avaliação do Astigmatismo Intra-Operatório............................................................ 20

Capítulo 3.................................................................................... 23

FORMALISMO MATEMÁTICO DA CERATOMETRIA E CERATÔMETROS

QUANTITATIVOS ..................................................................... 23

3.1 A Córnea e o Princípio Ceratométrico..................................... 23

3.2 O Modelo Esférico............................................................. 27

3.3 A Equação para Cálculos da Mira de Ceratometria............... 30

3.4 Ceratômetro Cirúrgico Quantitativo...................................... 31

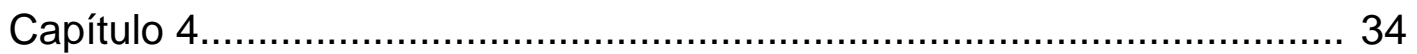

DESENVOLVIMENTO DO SISTEMA................................................ 34

4.1 Primeiro Sistema Desenvolvido........................................ 34

4.2 Segundo Sistema Desenvolvido....................................... 36

4.2.1 O Alvo de Capilares................................................. 37

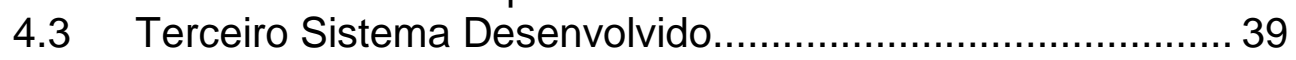

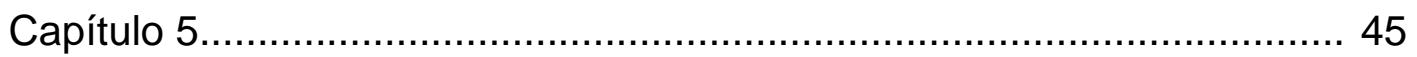

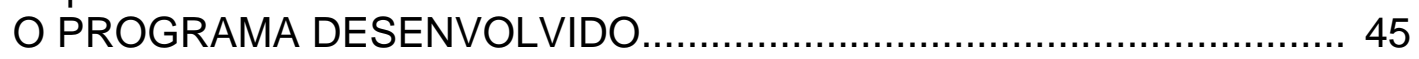

5.1 O Programa de Processamento da Imagem....................... 46

5.2 O Programa de Determinação da Ceratometria................... 47

5.3 Função Circularidade........................................................ 50

Excentricidade ....................................................... 50 
$5.4 \quad$ O Programa de Interface ................................................ 52

5.5 Programa de Calibração............................................... 54

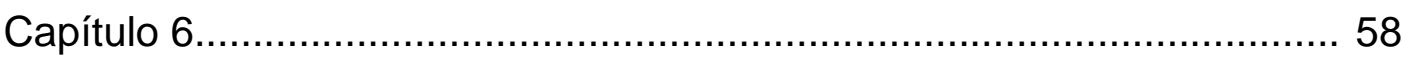

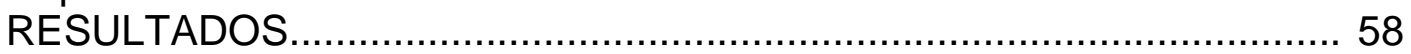

6.1 Avaliação das Precisões e Repetibilidade do Sistema........ 58

$6.2 \quad$ Profundidade de Foco...................................................6 66

6.3 Avaliação da Medida de Circularidade.............................. 67

6.4 Testes em Pacientes....................................................... 68

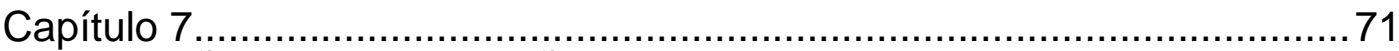

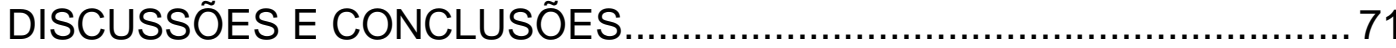

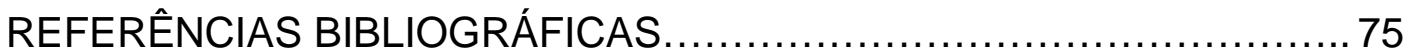




\section{INTRODUÇÃO}

\subsection{A CÓRNEA}

A esclera é a camada ocular mais externa e resistente, desta forma, confere proteção ao olho; esta se torna transparente em sua porção anterior, e assim, forma-se a córnea [ATCHISON, A.; et al; 2000]. A córnea é um tecido que não possui vasos sanguíneos e é abundante em células nervosas [DUKEELDER, 1970]. É responsável pela principal parte da refração ocular (cerca de $73 \%$ do poder refrativo total do olho), e constitui-se de uma lente convergente de 40 a 45 dioptrias. A luz é refratada acentuadamente na superfície anterior da córnea devido a sua curvatura - o terço central da córnea apresenta geralmente uma forma esférica com raio de curvatura externo de $7.8 \mathrm{~mm}$ em média - e também, devido à diferença entre os índices de refração do ar (1.0) e da córnea (1.38). A porção mais periférica da córnea é mais plana, radialmente assimétrica e mais espessa $(0.65 \mathrm{~mm})$ do que a porção central $(0.52 \mathrm{~mm})$.

A córnea é constituída por cinco camadas (Figura 1.1):

- Filme lacrimal;

- Epitélio;

- Estroma (incluindo a zona de Bowman);

- Membrana de Descemet; 
- Endotélio.

O filme lacrimal proporciona uma interface refrativa para a córnea ao preencher as depressões causadas pelos microvilos de membrana celular das células epiteliais. O epitélio (junto com a sua membrana basal) é a camada de células mais externa da córnea.

Imediatamente após o epitélio, tem-se o estroma, responsável por quase $90 \%$ da espessura corneana. O endotélio tem a importante função de manter uma barreira efetiva do humor aquoso, e conseqüentemente, criar condições para manutenção da transparência da córnea. O endotélio situa-se sob a membrana de Descemet.

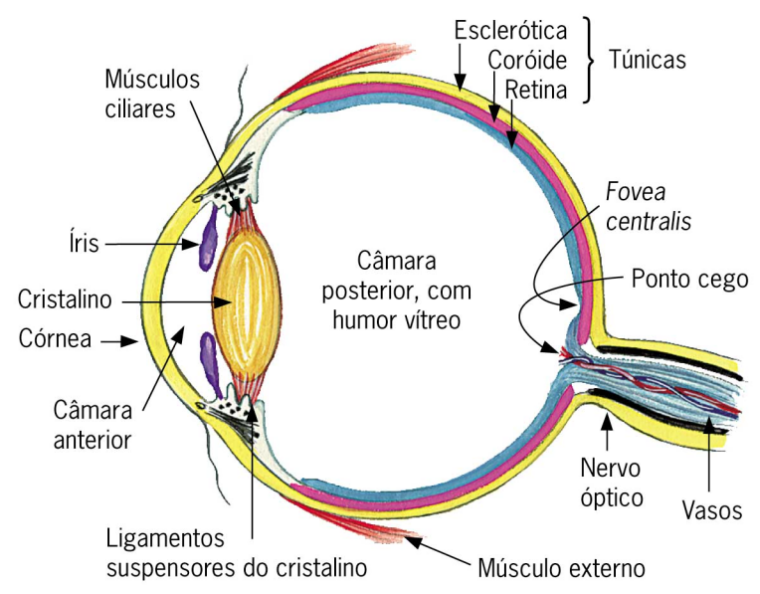

(a)

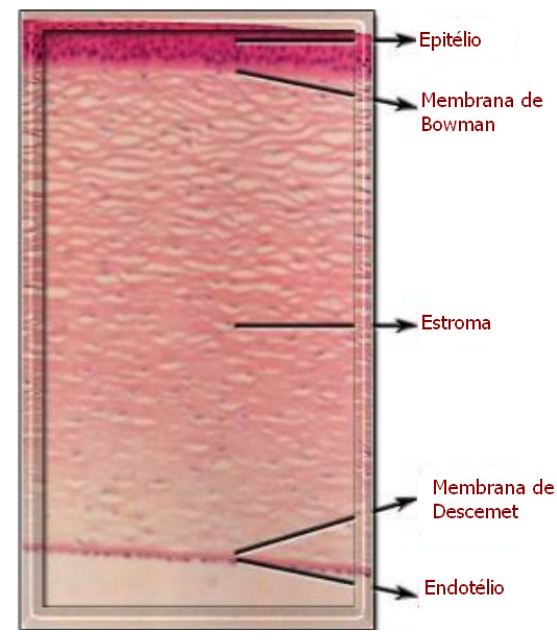

(b)

Figura $1.1 \quad$ (a) O olho humano (http://www.vision.ime.usp.br/ ronaldo/mac041703/aula_02/BIO2_329.jpg - acessado em 06/10/2007);

(b) As camadas da córnea (http://www.uniteforsight.org/course/image/cornea.jpg - acessado em 06/10/2007).

As regiões da superfície da córnea são anatomicamente classificadas mediante suas aplicações clínicas, assim, divide-se a córnea em regiões concêntricas: central, paracentral, periférica e límbica [ATCHISON, 2000]. A 4 
região central tem um diâmetro de até $4 \mathrm{~mm}$, medida aproximada do diâmetro pupilar e o seu centro é determinado pelo eixo pupilar. Esta região, também chamada zona ótica, é a mais importante no aspecto óptico, pois qualquer alteração nesta zona pode determinar menor acuidade visual, maior visão e outras anomalias funcionais. A região paracentral é formada por um anel que compreende a região entre $3-7 \mathrm{~mm}$ de diâmetro, é mais aplanada do que a zona central. Esta, juntamente com a zona central, constitui a zona apical, região fundamental à adaptação de lentes de contato. $\mathrm{O}$ anel compreendido entre 7 - 11mm de diâmetro constitui a zona periférica mais plana e ainda esférica.

A zona límbica situa-se em uma margem de $0.5 \mathrm{~mm}$ da córnea adjacente à esclera.

\subsection{O CERATÔMETRO}

O ceratômetro é um equipamento utilizado para medir o raio de curvatura da porção central da superfície anterior da córnea [MOHRMAN, R., 1981].

Hermann von Helmholtz [MANDELL, R.; 1960] é creditado com o desenvolvimento do primeiro ceratômetro em 1851. Os princípios de seu instrumento são empregados em todos os ceratômetros comerciais em uso atualmente. Melhoramentos e refinamentos clínicos foram feitos no fim do século XIX por Javal, Schiötz e outros [PRADO, D.; 1941; TATE, G. J.; et al; 1987]. Desenvolvimentos recentes no design ótico e mecânico dos 
ceratômetros têm conduzido a instrumentos modernos com os quais as medidas requeridas podem ser realizadas em poucos segundos [MANNING, C.A., et al; 1997; VENTURA, L., et al; 2003, 2005,2006].

Ceratômetros clínicos foram originalmente desenvolvidos para prover uma medida objetiva do astigmatismo da parte anterior da córnea. Esta informação era considerada útil para obtenção de uma estimativa do erro astigmático total do paciente. O desenvolvimento de técnicas de refração mais sofisticadas e precisas tornou tal informação menos importante. Mas, devido à popularização das lentes de contato durante a década de 1960, como um meio de correção de erros refrativos, requer-se que o clínico tenha conhecimento dos raios de curvatura da córnea para determinar o ajuste adequado das lentes. Desta forma, o ceratômetro tornou-se novamente um instrumento importante para o oftalmologista. Este é também útil no monitoramento de mudanças na forma da córnea, como o ceratocone (patologia cujo sinal mais expressivo é a deformidade em forma de cone da córnea [ALBERT, D.M., et al; 1994]).

O ceratômetro convencional possui vários aspectos positivos:

- precisão e reprodutibilidade para medidas em córneas regulares dentro de uma escala de curvaturas normais (40 - 52 dioptrias);

- rapidez relativa nas medidas;

- facilidade de uso;

- baixo custo;

- requisitos mínimos de manutenção.

Os ceratômetros são divididos em dois grupos: manual e automático.

O instrumento manual projeta quatro alvos luminosos na superfície corneana, estes são posicionados em quadrantes opostos de um círculo 
imaginário de 3mm de diâmetro [MOHRMAN, R., 1981]. As distâncias entre as imagens dos alvos correspondentes - medidas com prismas duplicadores e um microscópio de longa distância focal - são utilizadas para determinar o raio de curvatura da córnea. Apesar de prover uma faixa para medidas relativamente abrangente, este instrumento não é capaz de realizar medidas em algumas córneas que estão excepcionalmente distantes da média. Pode-se estender esta faixa de medidas através da disposição de lentes de testes em frente à lente objetiva do microscópio, porém esta é uma solução parcial, que tem como conseqüência uma diminuição na precisão.

O ceratômetro automático projeta uma mira circular luminosa em uma região de $3 \mathrm{~mm}$ da córnea central (a zona medida depende da curvatura da córnea, por exemplo, para uma córnea de 36 dioptrias, o ceratômetro mede uma região de $4 \mathrm{~mm}$; para uma córnea de 50 dioptrias, o tamanho desta zona é de 2.88mm [GREIVENKAMP, M.D., et al; 2000]), e analisa a imagem refletida. A distorção desta imagem - comparada à imagem circular de uma córnea normal, perfeitamente esférica e sem astigmatismo - proporciona a quantidade de astigmatismo e as direções dos meridianos principais da córnea, que são geralmente ortogonais. Estes fundamentos são a base da ceratometria automática [MOHRMAN, R., 1981].

Este instrumento mede a curvatura de qualquer meridiano da córnea com precisão de $\pm 0.01 \mathrm{~mm}$. Atualmente, os ceratômetros avançaram tecnologicamente, e alguns são equipados com anéis de projeção que cobrem toda superfície, proporcionando a topografia da córnea. Um ceratômetro moderno pode medir raios de curvatura de córneas, aproximadamente, a partir de $0.5 \mathrm{~mm}$ (distância a partir do eixo pupilar) a $12 \mathrm{~mm}$ em $0.01 \mathrm{~mm}$ de incremento (correspondente a um poder refrativo - medida proporcional ao 
inverso do raio de curvatura da córnea - de $28 \mathrm{D}$ a $60 \mathrm{D} \pm 1,25 \mathrm{D}$ ) e o eixo do astigmatismo corneano a partir de $0^{\circ}$ a $180^{\circ} \pm 1^{\circ} \quad$ [POLISUK, P.; 2003].

Cada um destes equipamentos possui seu próprio sistema ótico, alguns automáticos, mas apresentam para cada ótica exclusiva e individual, um alto custo de produção para esta classe de diagnóstico.

O ceratômetro apresenta algumas limitações:

- proporciona medidas apenas de uma pequena região da córnea (a zona central);

- assume que a córnea é simétrica, por esta razão, calcula a média dos dois semi-meridianos para qualquer meridiano da córnea;

- para córneas com diferentes poderes de refração, o ceratômetro mede diferentes regiões;

- há perda de precisão quando córneas muito planas ou muito curvas são submetidas ao exame, particularmente, aquelas com curvaturas superiores a $50 \mathrm{D}$.

A partir das limitações descritas acima, o ceratômetro fornece uma estimativa razoável da curvatura da região central para córneas normais regulares. Porém, demonstra pouca precisão em algumas condições clínicas, como: patologias não-conhecidas e córneas não-regulares; e córneas submetidas a algum trauma. 


\subsection{O MICROSCÓPIO CIRÚRGICO}

O microscópio cirúrgico é um instrumento essencial para a cirurgia oftálmica, devido a sua ótica para microscopia bem estabelecida e de boa qualidade. Os microscópios cirúrgicos oculares são constituídos de três elementos básicos: o biomicroscópio, o sistema de iluminação e um sistema mecânico [BARRAQUER, J. I.; 1980].

O biomicroscópio consiste em um microscópio binocular que permite a observação da imagem ampliada do olho. O binóculo é inclinado para limitar a distância entre o paciente e o cirurgião e esta não deve exceder $350 \mathrm{~mm}$. Embora, o microscópio tenha um mecanismo de inclinação, a composição óptica deve ser vertical à córnea durante as cirurgias, porque o ceratômetro cirúrgico não é preciso em posição inclinada. A lente objetiva, de distância focal de $200 \mathrm{~mm}$, valor encontrado na maioria dos modelos comerciais, garante uma distância de trabalho confortável ao cirurgião e segura ao paciente. O conjunto de lentes, responsável pelo zoom óptico, permite mudanças convenientes de alguns valores de magnificação da imagem. O sistema de zoom do microscópio deve possuir um intervalo de magnificação de aproximadamente $4 \mathrm{X}$ a 18X. Os aumentos mais baixos, até $6 \mathrm{X}$, são usados para propósitos de identificação. $\mathrm{A}$ maioria das cirurgias é realizada entre $6 \mathrm{X}$ e 12X. Magnificações acima de 12X são úteis para aumentar a precisão do ceratômetro cirúrgico e para inspecionar irregularidades na região de incisão-sutura.

O sistema de iluminação constitui-se de uma fonte de luz, que possui ajustes de intensidade para manter a iluminação adequada ao trabalho de cada cirurgião. Este sistema de iluminação é oblíquo, e desta forma, menos 
cansativo ao cirurgião e menos prejudicial à mácula do paciente, oferece melhores detalhes de sombra e visão estereoscópica durante cirurgias de manobra de corte preciso e sutura necessária.

O sistema mecânico proporciona estrutura às duas outras partes, de forma a possibilitar uma cirurgia. O corpo do microscópio deve ser suspenso a partir de um sistema para auto-centragem $\mathrm{X}-\mathrm{Y}$, manipulado por um controle motorizado, a partir do acionamento de um pedal. Este pedal também deve possuir controles para zoom de foco fino, inclinação e para ligar e desligar o sistema de iluminação.

Para incorporar um sistema de vídeo, o microscópio cirúrgico ocular (figura 1.2a) deve ser provido com um divisor de feixe (Figura 1.2b), geralmente com a relação de $70 \% / 30 \%$ de imagem para o clínico e para o vídeo, respectivamente.

Assim, o objetivo deste trabalho é unir a ótica de excelente qualidade do microscópio cirúrgico a um componente extra, o módulo para ceratometria, permitindo acrescentar ao microscópio cirúrgico uma função objetiva e quantitativa, a ceratometria transoperatória.
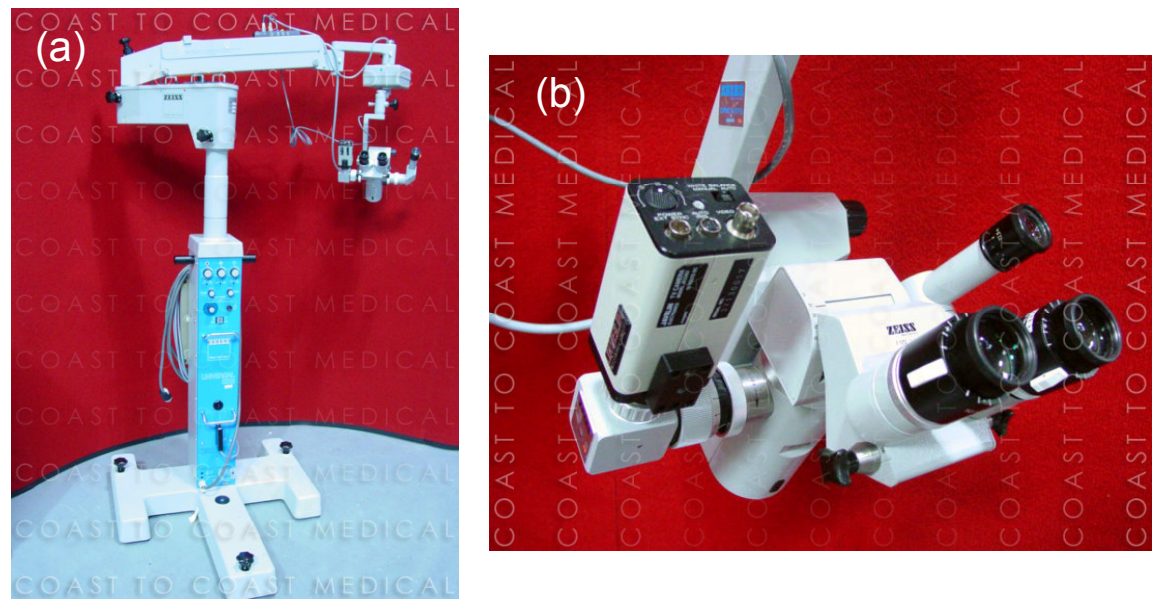

Figura 1.2 (a) Microscópio cirúrgico da marca Zeiss;

(b) Detalhe do microscópio com câmera de vídeo acoplada (www.zeiss.com - acessado em 


\section{O ASTIGMATISMO E OS SISTEMAS INTRA-CIRURGICOS}

\subsection{O ASTIGMATISMO E SUAS CORREÇÕES}

O astigmatismo é um defeito da visão geralmente devido à não esfericidade da superfície da córnea; o raio de curvatura dessa superfície não é o mesmo em todos os meridianos - assemelha-se a uma bola de futebol americano (elipsóide), onde os meridianos de maior e menor curvaturas estão a $90^{\circ}$. O astigmatismo faz com que seja impossível, por exemplo, focalizar simultaneamente as barras horizontais e verticais de uma janela.

Assim, o astigmatismo é a condição de refração onde feixes de luz, provenientes de uma fonte luminosa pontual situada no infinito, paralelamente incidentes em diferentes meridianos, formam imagens em diferentes posições no eixo ótico (pontos focais diferentes para cada meridiano entre $0^{0}$ e $180^{\circ}$ figura 2.1).

O astigmatismo pode ser um erro de curvatura, de centralização ou do índice de refração [SPALTON, D.J.; et al; 2005].

O astigmatismo de curvatura, se de um grau mais intenso, tem sua origem mais freqüente na córnea. A anomalia é em geral congênita e as medidas oftalmométricas mostram que a sua ocorrência em pequenos graus é comum. O erro mais freqüente é aquele em que a curva vertical é maior que a horizontal ("meridiano mais curvo" de aproximadamente 0,25di). Este é 
conhecido como astigmatismo direto ("a favor da regra"), e é aceito como fisiológico; presumivelmente se deve a uma pressão constante da pálpebra superior sobre o olho. Marin Amat [Spalton, D.J.; et al; 2005] descobriu que, enquanto no nascimento a córnea é normalmente quase esférica, este tipo de astigmatismo está presente em $68 \%$ das crianças aos 4 anos de idade, e em $95 \%$ aos 7 anos. Há evidência de que tende a aumentar em grau muito discreto nos anos seguintes; porém, com a idade, tende a desaparecer ou mesmo tornar-se em astigmatismo inverso ("contra a regra"), com a curvatura vertical menor do que a horizontal.

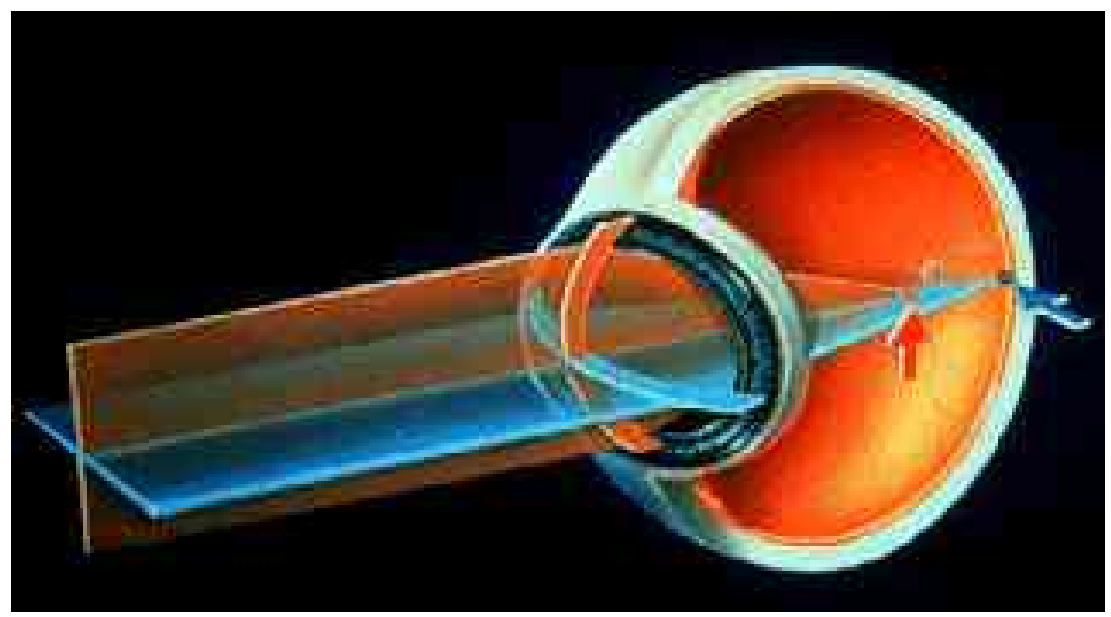

Figura 2.1 Representação esquemática do astigmatismo (http://www.sac.org.br/APR_DO.htm, acessada em 10/09/2007).

\subsection{TIPOS DE ASTIGMATISMO}

$\mathrm{O}$ astigmatismo em que os dois meridianos principais encontram-se em ângulos retos e que é, portanto, passível de correção, é denominado de regular. Na grande maioria desses casos, os meridianos de maior e menor 12 
curvatura estão próximos ou realmente verticais e horizontais ou vice-versa. Caso isso não ocorra desse modo e uma vez que o meridiano maior e o menor estejam em ângulos retos, teremos então um astigmatismo regular que denominamos astigmatismo oblíquo. Quando os eixos não se encontram em ângulos retos, mas são cruzados obliquamente, o sistema ótico é ainda passível de resolução numa combinação esferocilíndrica, e a condição pode ser denominada de astigmatismo bioblíquo; não é de ocorrência muito comum.

Quando existem irregularidades na curvatura dos meridianos de forma que nenhuma figura geométrica adere aos mesmos, a condição é denominada astigmatismo irregular; não permite sua correção adequada por óculos.

\subsubsection{Astigmatismo Regular}

O astigmatismo regular pode ser classificado em astigmatismos: simples, composto e misto. A figura 2.2 ilustra estes astigmatismos, onde as semi-retas representam as focais horizontais e verticais. Os astigmatismos são definidos como:

1. astigmatismo simples, onde um dos focos incide sobre a retina. $O$ outro foco pode incidir na frente ou atrás da retina, de forma que enquanto um meridiano é emétrope, o outro é hipermétrope ou míope. Estes são, respectivamente, designados de astigmatismo hipermétrope simples e míope simples. 
2. astigmatismo composto, onde nenhum dos dois focos localiza-se sobre a retina, porém ambos localizam-se na frente ou atrás dela. O estado da refração é inteiramente hipermétrope ou inteiramente míope. O primeiro é conhecido como astigmatismo hipermétrope composto, e o último como astigmatismo míope composto.

3. astigmatismo misto, onde um foco localiza-se na frente e outro atrás da retina, de forma que a refração é hipermétrope em uma direção e míope na outra.

O tipo habitual fisiológico de astigmatismo, onde a curva vertical é maior do que a horizontal, é denominado de astigmatismo direto ou astigmatismo "com a regra"; em caso inverso, trata-se de um astigmatismo indireto ou astigmatismo "contra a regra".

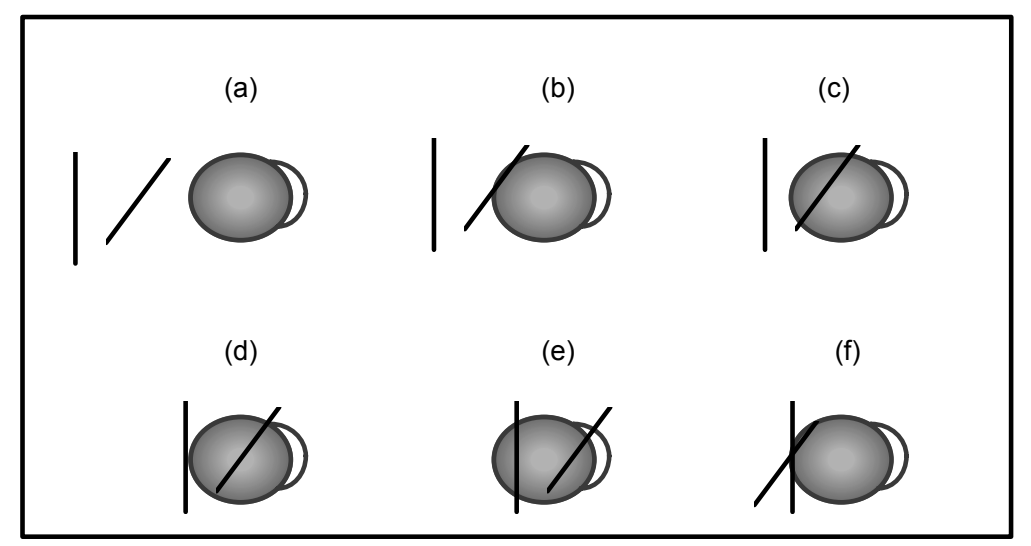

Figura 2.2 Classificação dos astigmatismos regulares: (a) hipermétrope composto; (b) hipermétrope simples; (c) misto; (d) míope simples; (e) míope composto; (f) sem astigmatismo [VENTURA, L.; 2007]. 


\subsection{O CÍRCULO DE MENOR CONFUSÃO}

Um objeto pontual luminoso incide em uma lente astigmática e forma imagens em um anteparo. O conjunto de raios luminosos que forma as imagens de elipses e das duas linhas (mostradas ao longo do eixo óptico da Figura 2.3) é denominado Conóide de Sturm [DUKE-ELDER, 1970]. Desta forma, verifica-se o efeito das propriedades convergentes dos dois meridianos da lente, atuando como duas lentes independentes.

Colocando-se o anteparo, paralelo ao plano da lente, na posição da seta azul, observar-se-á uma linha vertical como imagem. Agora, ao movê-lo para a posição da seta laranja, formar-se-á uma linha horizontal. Estas duas posições são chamadas linhas focais, e estão separadas entre si pelo intervalo focal de Sturm. Entre essas duas posições, várias imagens formar-se-ão, como ilustrado. O comprimento deste intervalo é uma medida do grau de astigmatismo e a correção do erro é obtida reduzindo-se estes dois focos em um único [ATCHISON, A.; et al; 2000].

Porém, existe a posição onde se tem a imagem de um círculo, denominada círculo de menor confusão (ou difusão). O círculo de menor confusão (ou interfocal) está no ponto intermediário, dioptricamente, entre os dois pontos focais extremos (linha horizontal e vertical), onde é formada uma imagem "borrada", com o menor grau de distorção e deformações mais simétricas possíveis. É exatamente esta imagem, que o astigmata tenta manter sobre a retina, através da acomodação visual [Atchison, A.; et al; 2000]. 


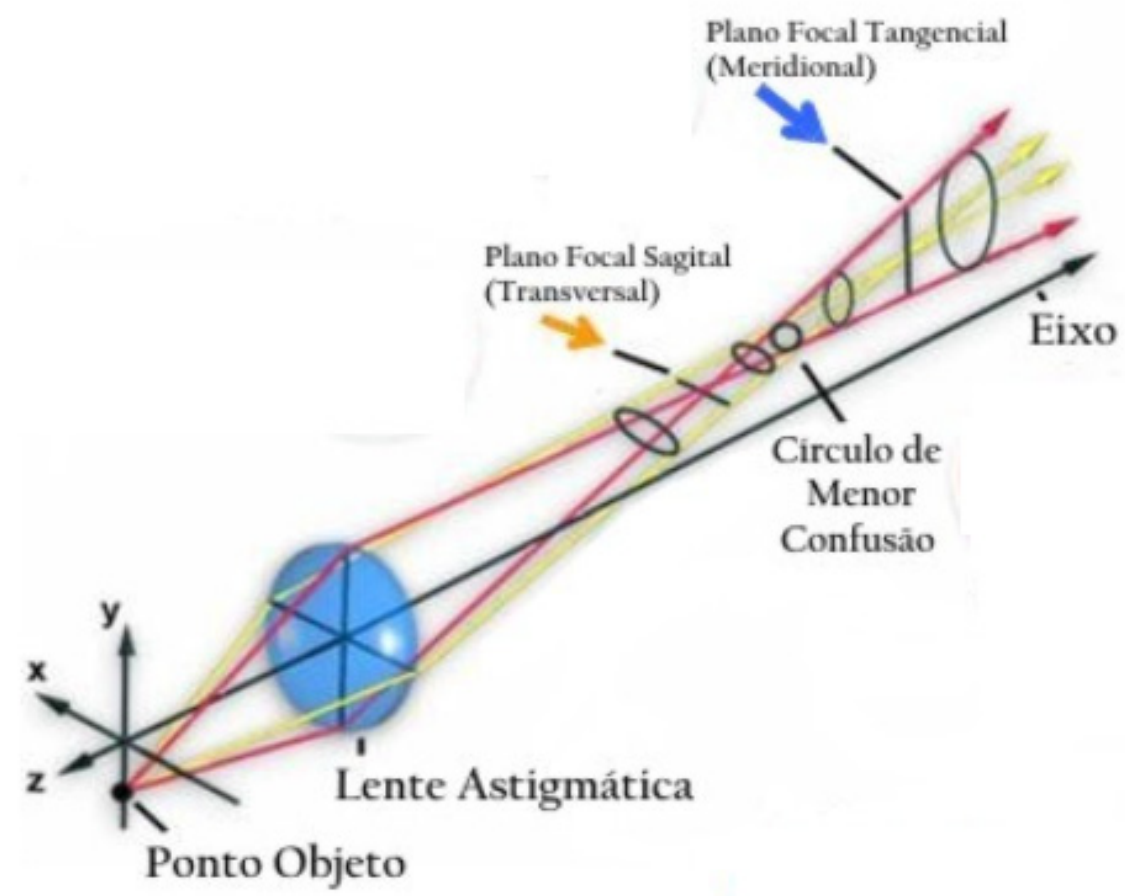

Figura 2.3 Representação do Círculo de Menor Confusão (http://micro.magnet.fsu.edu/primer/images/aberrations/astigfigure2.jpg - acessada em 06/10/2007)

Uma esfera é uma superfície em que todos os seus meridianos possuem a mesma curvatura, desta forma, os raios que provêm de um ponto podem ser focalizados na forma de um ponto (Figura 2.4a). Além disso, as propriedades de focalização de uma lente esférica são invariantes à rotação em torno de seu 
eixo óptico central. Assim, lentes esféricas são empregadas para correção das ametropias de miopia e hipermetropia.

No entanto, nem todas as superfícies são esféricas, estas são as superfícies astigmáticas. A Figura 2.4b ilustra um tipo particular de superfície não-esférica, tais superfícies são denominadas toroidais. Estas superfícies são caracterizadas por dois raios de curvatura distintos, dispostos perpendicularmente entre si.

Pode-se imaginar uma lente astigmática mais complexa na qual ambos os meridianos são curvos, porém, em graus diferentes (Figura 2.4c e Figura 2.4d). Conclui-se, portanto, que uma lente astigmática deste tipo, devido a diferentes curvaturas de seus meridianos, nunca produzirá o ponto focal de um ponto-objeto. As propriedades de refração de uma lente desta natureza podem ser verificadas na Figura 2.3 e ilustra, por analogia, o modo pelo qual ocorre a refração dos raios luminosos paralelos em um olho astigmático.

Um cilindro também pode ser considerado uma superfície toroidal, porém com $\mathbf{r}_{2}$ infinitamente longo. Uma lente cilíndrica (ou plano-esférica) se forma ao cortar uma porção de uma esfera sólida por um plano. É, assim, recurvada no meridiano horizontal (com raio de curvatura finito), no qual atua como uma lente esférica, e plana no vertical, no qual atua como uma lâmina com faces paralelas (com raio de curvatura infinito), este último meridiano é denominado eixo. Uma das características do cilindro é que o feixe de luz incidente, proveniente de um ponto, é refratado de modo a formar uma linha correspondente, paralela ao eixo do cilindro, ou seja, a cada ponto incidente, há uma linha refratada correspondente. Deve-se lembrar que a luz, quando incide paralela ao eixo de revolução do cilindro, não sofre desvio, mas os raios 
que incidem em ângulos retos em relação ao eixo são refratados do mesmo modo que por uma lente esférica.

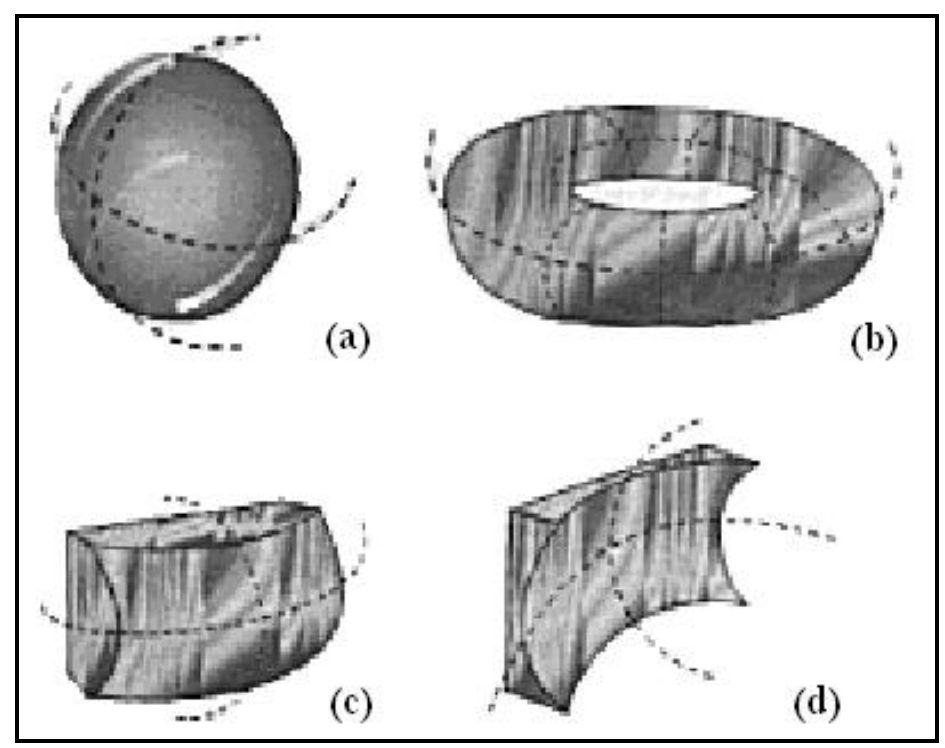

Figura 2.4 Representação de superfícies: (a) esféricas; (b) toroidais; (c) cilíndrica positiva (ou convexa); (d) cilíndrica negativa (ou côncava) [VENTURA, L.; 2007].

Desta forma, se os dois meridianos principais de um olho com astigmatismo estiverem em ângulos retos entre si, o erro pode ser corrigido pelo emprego de uma lente cilíndrica adequada que, atuando no plano de um meridiano, modificará a refração dos raios que são dirigidos para um foco à mesma distância que aqueles do outro meridiano, quando então toda a imagem transformar-se-á em um ponto na retina. 


\subsection{O ASTIGMATISMO E O TRANSPLANTE DE CÓRNEA}

O astigmatismo também pode ser adquirido, devido uma patologia da córnea, que resulta em sua deformidade; ou por traumatismo cirúrgico, como operações de catarata e cirurgias de transplante de córnea. Por isso, o astigmatismo é uma das mais freqüentes causas de baixa acuidade visual póstransplante de córnea. Astigmatismos excessivos, irregulares (nesta situação, os meridianos não se encontram em ângulos retos) ou assimétricos (ou seja, a córnea apresenta curvatura diferente em dois semi-meridianos de um mesmo meridiano) são habitualmente encontrados pós-transplante de córnea, desta forma, mostram-se como um dos principais motivos de insucesso funcional desta intervenção cirúrgica. Em alguns casos, o astigmatismo é tão severo ou irregular, que impossibilita a correção óptica com óculos, podendo ainda condicionar anormalidades do filme lacrimal e dificuldade na adaptação de lentes de contato. São muitas as causas que podem induzir o astigmatismo em uma cirurgia de transplante de córnea, como: cicatrização irregular, irregularidade ou desequilíbrio da tensão das suturas. Assim, este trabalho objetiva atenuar $\mathrm{o}$ astigmatismo induzido pelas suturas, de forma que 0 astigmatismo residual seja apenas o devido a outros fatores. 


\subsubsection{Sistemas Existentes para Avaliação do Astigmatismo Intra- operatório}

É preciso ressaltar os métodos e fundamentos dos recursos de técnica cirúrgica que são empregados na prevenção e minimização intra-cirúrgica e na análise e tratamento do astigmatismo adquirido, para compreender as bases da composição do presente trabalho.

Os mecanismos indutores de astigmatismo, mais especificamente, em uma cirurgia de transplante de córnea, além de atuarem isoladamente, podem se apresentar em número de dois ou mais, e desta forma, produzem-se múltiplas combinações. O conhecimento detalhado desses mecanismos orienta o cirurgião para melhor utilizar os recursos de técnica cirúrgica, de forma a anular os diferentes mecanismos à medida que são detectados.

Após várias manipulações intra-oculares realizadas para a retirada do botão da córnea do receptor (do paciente), o botão da córnea do doador deve ser recolocado e suturado. Para prevenir a indução de astigmatismo por suturas com tensões assimétricas utiliza-se a ceratoscopia transoperatória, com Discos de Plácido, que consiste em um disco plano com faixas concêntricas alternadas em preto e branco. Deve ser posicionado na frente da córnea do paciente e o cirurgião observa, através de uma abertura central, o reflexo na lágrima da superfície anterior da córnea que, pela deformação da imagem, aponta a deformidade da imagem [CVINTAL, T.; 2004]. As substituições das suturas defeituosas (frouxas ou apertadas) por suturas adequadas, e o monitoramento repetido com a ceratoscopia devem gradualmente minimizar o astigmatismo. Assim, ao concluir a cirurgia com uma imagem circular do ceratoscópio, astigmatismos inferiores a 2D são obtidos. 
Além da ceratoscopia transoperatória com Discos de Plácido, pode-se empregar um método eficaz, confiável e barato, que é o método do ceratoscópio de círculo-de-arame ("wire-loop keratoscope", que consiste em um cabo com um círculo de arame em uma de suas extremidades) [WHITSON, W.E.; et al; 1994]. O círculo-de-arame é mantido pelo cirurgião por volta de 2cm diretamente acima e paralelo ao plano da córnea. A irrigação do botão doador suturado no paciente suaviza tal superfície, e assim torna-se possível visualizar a reflexão do círculo-de-arame na córnea. Retirado o excesso de irrigação da córnea, qualquer desvio desta reflexão de um círculo perfeito indica subjetivamente o astigmatismo no enxerto. Freqüentemente, a reflexão é uma elipse, e o eixo mais curto representa o meridiano de maior curvatura da córnea. As suturas isoladas devem ser removidas deste eixo e substituídas por suturas menos apertadas, exceto as suturas frouxas que podem ser identificadas no meridiano menos curvo, as quais devem então ser substituídas por suturas mais apertadas (este mesmo procedimento é realizado para a ceratoscopia com Discos de Plácido). A ceratoscopia é repetida com a substituição das suturas incorretas para prevenir e minimizar o astigmatismo transoperatório.

Os métodos de ceratoscopia apresentados possuem o inconveniente de apenas fornecer informações qualitativas e subjetivas, de acordo com as distorções observadas no reflexo dos objetos empregados (Discos de Plácido ou círculo-de-arame). Deve-se saber que pequenas variações na circularidade da região central da córnea, significam já um grau razoável de astigmatismo. Portanto, estes sistemas são bastante falhos.

Os ceratômetros cirúrgicos qualitativos projetam objetos de formato circular na superfície da córnea e a imagem, formada por sua reflexão, é 
analisada de maneira semelhante à ceratoscopia. Dentre esta classe de instrumentos, podem-se citar alguns exemplos: o Ceratômetro de Malloney [IGARASHI, H.; 1991], consiste em uma série de discos concêntricos de tamanhos decrescentes (os Discos de Plácido) projetados sobre toda a superfície da córnea, mantidos a uma pequena distância da mesma; o Anel de Flieringa (Figura 2.5a), iluminado pela própria luz do microscópio, oferece boa estimativa qualitativa do astigmatismo intra-operatório [BALLIN, N.; 1981]; o Ceratômetro de Troutman (Figura 2.5b) - [TROUTMAN, R.; 1977; 1987], constitui-se de um anel circular de 12 pontos iluminados colocados ao redor da lente objetiva do microscópio, a imagem formada pelo reflexo destes pontos era comparada a uma grade circular, colocada em uma das oculares do binóculo; já o Ceratômetro de Cravy emprega uma fonte de luz fluorescente para projeção de um círculo de luz contínuo, este ceratômetro é suspenso por cabos acoplados ao microscópio cirúrgico e pode ser movimentado para modificação do diâmetro do círculo, permitindo, desta forma, a análise da curvatura da córnea central, paracentral e periférica [CRAVY, T. V. ; et al, 1979].

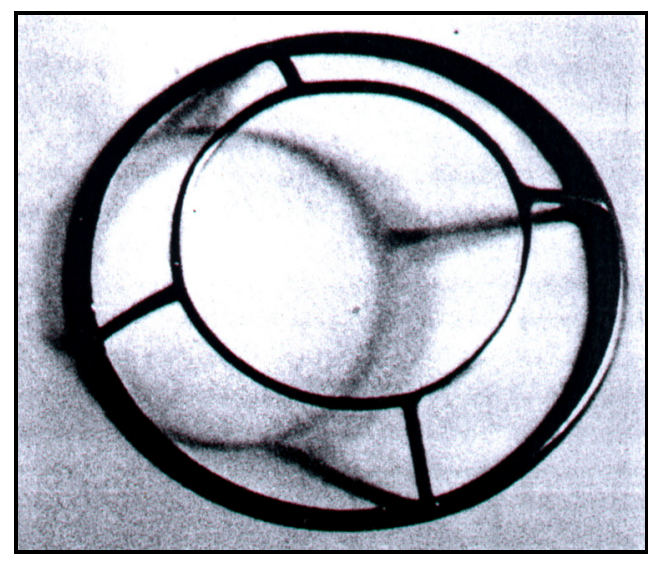

(a)

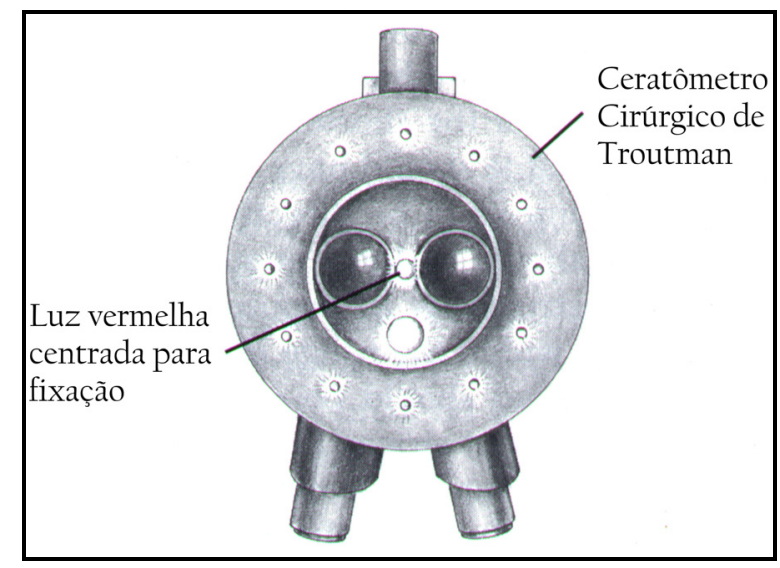

(b)

Figura 2.5 (a) Anel de Flieringa; (b) Visão do paciente do Ceratômetro de Troutman; 
Capítulo 3

\section{FORMALISMO MATEMÁTICO DA CERATOMETRIA E CERATÔMETROS QUANTITATIVOS}

\subsection{A CÓRNEA E O PRINCÍPIO CERATOMÉTRICO}

A forma da superfície anterior da córnea é aproximadamente uma esfera, ou em casos de uma córnea com astigmatismo, a mesma assume uma forma esfero-cilíndrica [GORMLEY, D. J.; 1988]. Os ceratômetros medem somente áreas relativamente pequenas da córnea, aproximadamente $3 \mathrm{~mm}$ de diâmetro (com o centro determinado pelo eixo pupilar). Para tais pequenas áreas, sua superfície aproxima-se bem a uma superfície esférica ou esferocilíndrica e são medidas, desta forma, com o ceratômetro.

Para compreender o princípio do ceratômetro, a formação de imagens por espelhos convexos é mostrada na Figura 3.1. Na Figura 3.1(a), um objeto representado por uma flecha (à direita da figura) é mostrado a alguma distância de um espelho convexo com raio de curvatura $R_{1}$. Três raios são traçados a partir de um ponto do objeto em direção ao espelho. $O$ raio superior atinge o espelho convexo e é refletido ainda mais para cima. O raio central é refletido sobre ele mesmo e o raio inferior é refletido para baixo. Uma imagem virtual do 
objeto é formada, como mostrada, atrás da superfície refletora e é menor do que o objeto.

Na Figura 3.1(b), o mesmo objeto é colocado à mesma distância de um outro espelho convexo com um raio de curvatura menor, $R_{2}$. Pelo traçado de raios, a partir de um ponto do objeto, como anteriormente, uma imagem pode ser novamente localizada. Percebe-se, contudo, que esta segunda imagem é menor do que a primeira. Desta maneira concluí-se que, para um dado tamanho de objeto colocado a uma dada distância a partir de um espelho convexo, o tamanho da imagem formada depende do raio de curvatura do espelho.

A Figura 3.2 ilustra uma situação um pouco diferente, com os dois mesmos espelhos, $R_{1}$ com raio de curvatura maior (Figura 3.2(a)) e $R_{2}$ com raio de curvatura menor (Figura 3.2(b)). As duas imagens são de tamanho idêntico e a distância entre os espelhos e seus objetos é a mesma. Pode ser visto com o traçado de raios que, para o espelho de raio de curvatura maior $R_{1}$, o objeto deve ter uma dimensão particular para formar uma imagem com a dimensão desejada. Para o espelho de raio de curvatura menor $R_{2}$, o objeto deve ser maior para formar uma imagem do mesmo tamanho. Portanto, para um tamanho de imagem fixo e uma distância entre o objeto e o espelho fixa, o tamanho do objeto requerido depende do raio de curvatura do espelho. 

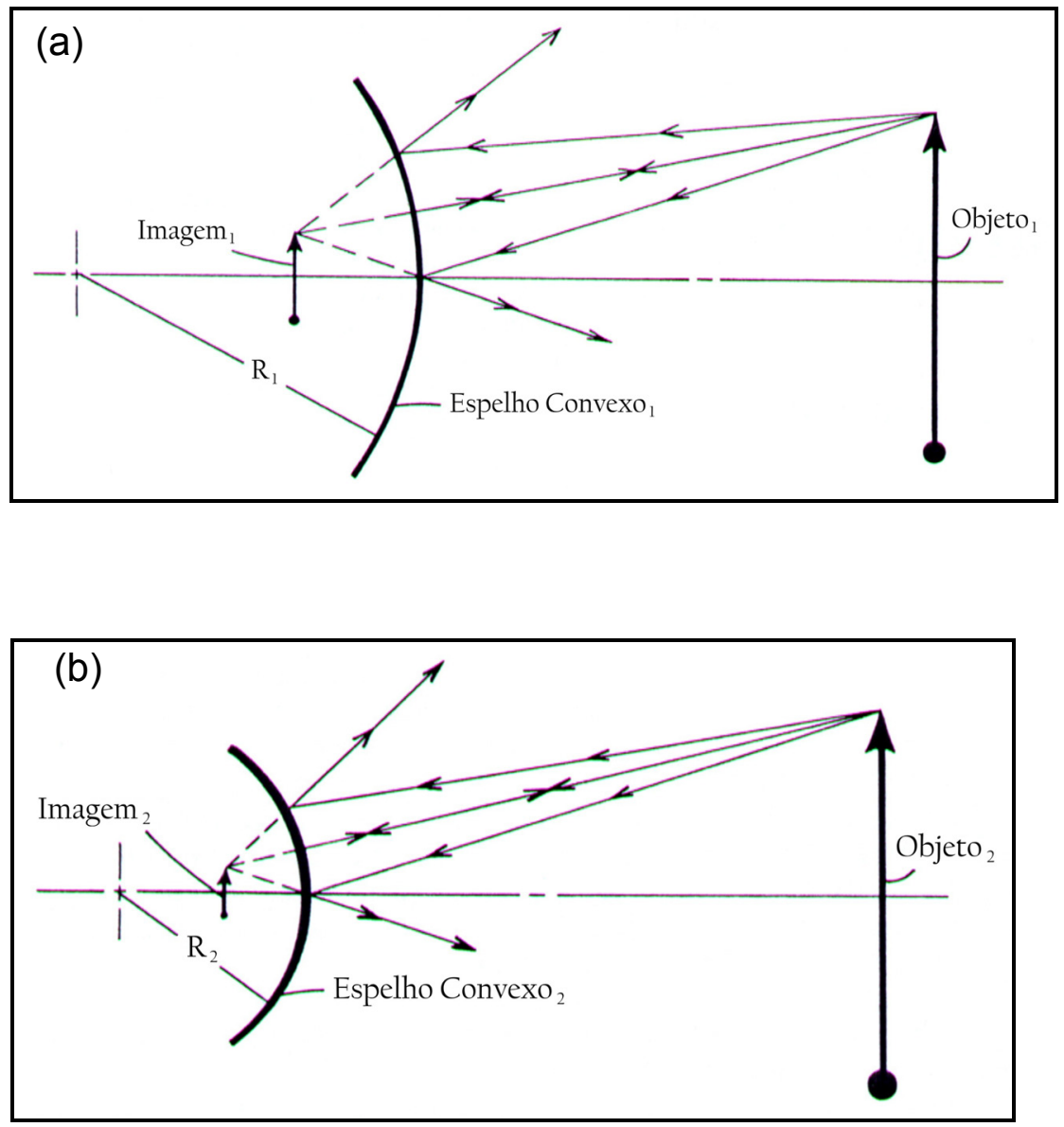

Figura 3.1 Formação de imagens por espelhos convexos, com tamanho do objeto constante e de imagem variável [HECHT, E.; 1990].

A equação 3.1 descreve matematicamente a formação de imagens por espelhos esféricos:

$$
\frac{1}{p}+\frac{1}{q}=\frac{1}{f}=\frac{2}{r}
$$

Onde, p é a distância do objeto ao espelho; q é a distância da imagem ao espelho; f é a distância focal do espelho; e $\mathbf{r}$ é o raio de curvatura do espelho. 

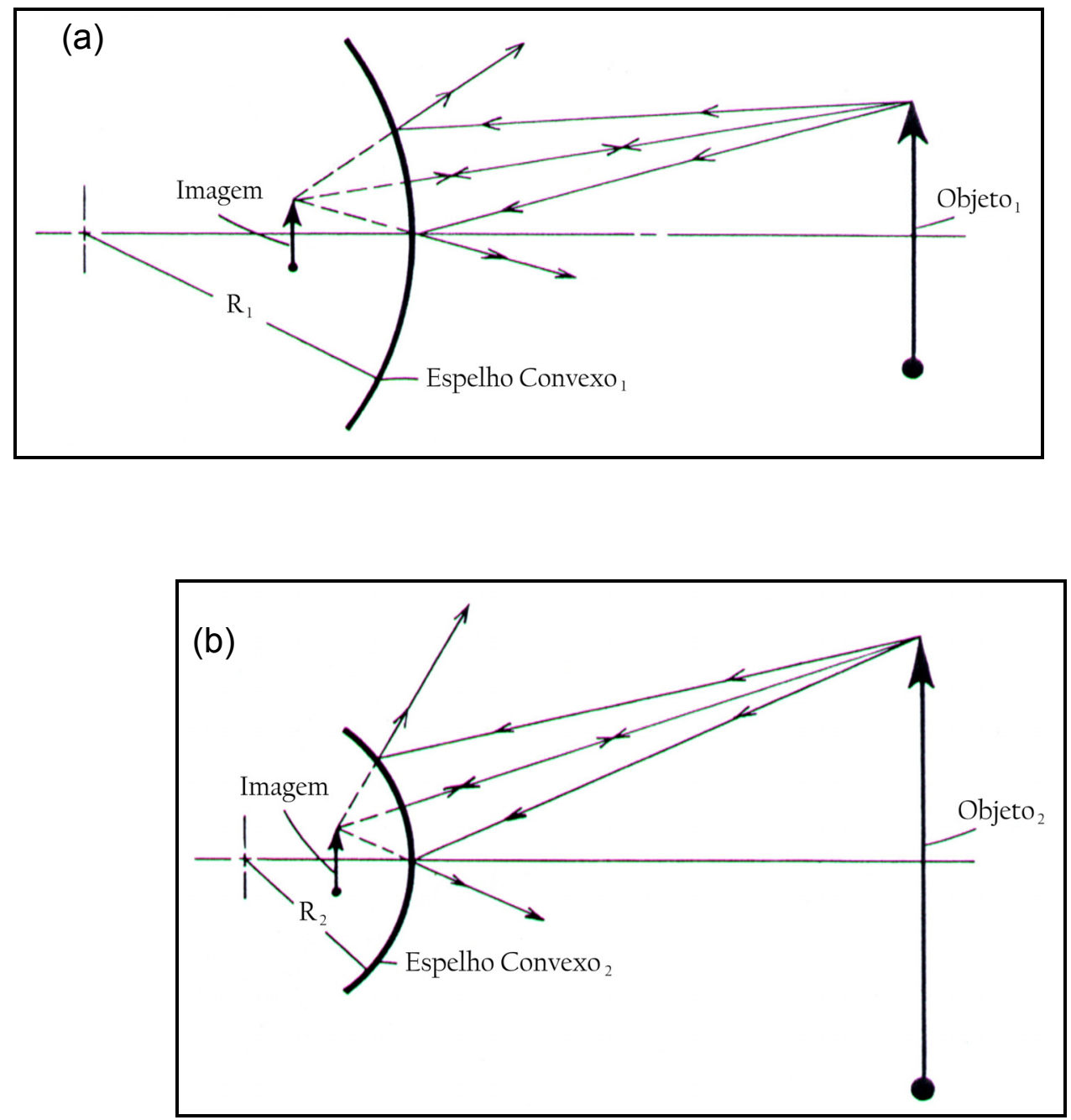

Figura 3.2 Formação de imagens por espelhos convexos, com tamanho da imagem constante e tamanho de objeto variável. [HECHT, E.; 1990].

No caso de um espelho convexo, os valores de $\mathbf{r}$ e $\mathbf{f}$ são negativos. A magnificação (M), produzida por um espelho, é a razão do tamanho da imagem pelo tamanho do objeto (Equação 3.2):

$$
M=\frac{\text { tamanho da imagem }}{\text { tamanho do objeto }}=\frac{q}{p}
$$


Para efeitos de ceratometria, a superfície anterior da córnea se comporta como um espelho convexo equivalente aos ilustrados nas Figuras 3.1 e 3.2. Os ceratômetros são fundamentados na base de tamanho de objeto constante (Figura 3.1) ou de tamanho de imagem constante (Figura 3.2).

A curvatura da córnea é freqüentemente não-esférica. Em muitos casos, a sua forma é aproximadamente tórica (uma córnea altamente astigmática possui forma similar a uma "rosca"). O raio da córnea varia através de seus meridianos em torno de seu eixo pupilar. Conseqüentemente, o ceratômetro deve ser capaz de medir os raios de curvatura em vários meridianos em torno do eixo da córnea. Para isso, os instrumentos são projetados de forma que o objeto empregado possa ser rotacionado com relação ao eixo. Os objetos empregados nos ceratômetros são de várias formas e são freqüentemente denominados como miras.

\subsection{O MODELO ESFÉRICO}

A zona central da córnea, onde a mira ceratométrica circular luminosa é projetada (região de $3 \mathrm{~mm}$ de diâmetro) é esférica e pode ser considerada, portanto, como um espelho esférico.

A Figura 3.3 mostra um diagrama esquemático do princípio ceratométrico [VENTURA, L.; 2007].

Um objeto de tamanho h (raio da mira circular) é posicionado a uma distância a da córnea e é perfeitamente focalizado junto à córnea. 
O reflexo do objeto $\mathrm{h}$ produz uma imagem virtual $\mathrm{y}$, que é a metade da dimensão do alvo projetado na córnea (em torno de 1,5mm) e está a uma distância b da sua superfície.

A distância $d$ do microscópio cirúrgico (Carl-Zeiss) que utilizamos neste trabalho é de $200 \mathrm{~mm}$ - cada microscópio possui uma distância específica de focalização. A dimensão b é a distância entre a superfície da córnea e a posição da imagem virtual do objeto (mira projetada).

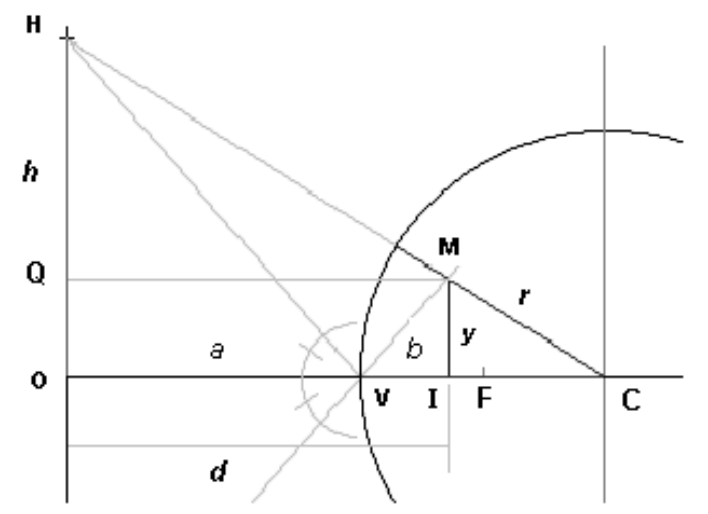

Figura 3.3 Diagrama esquemático do princípio da ceratometria.

Considerando que os feixes de luz provenientes de $\mathrm{h}$ incidam no eixo óptico com ângulos pequenos, é possível dizer que a distância focal é metade do raio de curvatura da córnea (r). Considerando os triângulos HOV e VIM, pode-se obter a relação :

$$
\frac{y}{h}=\frac{b}{a}
$$


Relacionando os triângulos HCO e HQM, tem-se:

$$
\frac{h}{a+r}=\frac{y}{r-b}=\frac{h-y}{a+b}
$$

Sendo

$$
d=a+b
$$

o raio de curvatura da superfície a ser determinado é:

$$
r=\frac{2 d h y}{h^{2}-y^{2}}
$$

Os resultados ceratométricos são geralmente apresentados em "poder de refração" (F), dado pela expressão (3.7) e a unidade é expressa em dioptrias (D).

$$
F=\frac{n_{c}-1}{r}
$$

onde $\mathrm{n}_{\mathrm{c}}$ é o índice de refração da córnea.

Até os dias atuais existe um debate na literatura sobre o índice de refração apropriado a ser utilizado. Pode-se utilizar 1,33, próximo ao índice de 
refração da água ou do fluido da lágrima, ou até mesmo 1,376, sendo o índice médio do tecido corneano. A escolha depende dos propósitos de calcular a curvatura e o poder óptico. Geralmente, para as medidas ceratométricas é escolhido o índice 1,3375 [JONGSMA, F.H.M.; 1999].

A equação paraxial (3.7) fornece o poder de refração da superfície corneana para os feixes que incidem aproximadamente normais à córnea e é válida apenas para a sua zona central.

\subsection{A EQUAÇÃO PARA CÁLCULOS DA MIRA DE CERATOMETRIA}

Para determinar a dimensão do anel de ceratometria, isola-se a variável h na Equação 3.6, assim:

$$
h=\frac{y\left(d+\sqrt{d^{2}+r^{2}}\right)}{r}
$$

Uma vez que, $d=a+b$, e com:

$$
\begin{aligned}
& r=7.86 \mathrm{~mm} \\
& d=200 \mathrm{~mm} \\
& y=1.5 \mathrm{~mm}
\end{aligned}
$$

O raio da mira a ser construída depende da escolha do valor de d (que é a distância entre a mira e a córnea), já que, como se trata de uma mira 
ceratométrica, y é igual a $1.5 \mathrm{~mm}$ e o valor $\mathbf{r}$ é o raio de curvatura de uma córnea ideal de valor 7.8mm [DUKE-ELDER S,; 1970].

\subsection{CERATÔMETRO CIRÚRGICO QUANTITATIVO}

Para realizar procedimentos cirúrgicos clínicos é essencial que o cirurgião tenha acesso às propriedades óticas da córnea do olho sob cirurgia. É particularmente importante que aquelas propriedades óticas que definem o astigmatismo corneano (i.e., o poder de refração e o eixo do astigmatismo) fiquem sob controle do cirurgião para a realização das suturas da cirurgia de catarata, transplante de córnea, implantação de lentes intra-oculares, etc, no intuito de minimizar o astigmatismo induzido por este procedimento.

Os ceratômetros e os oftalmômetros são amplamente utilizados para medir o raio de curvatura da córnea. O princípio básico típico de um ceratômetro consiste em refletir um anel de luz em uma superfície convexa espelhada de uma córnea úmida e analisar ou processar esta imagem refletida, para se obter informações sobre o raio de curvatura da córnea e a condição astigmática da córnea.

As cirurgias oftálmicas envolvem uma manipulação do tecido corneano muito precisa, delicada e com precisão de minutos nos eixos da sutura. Estas cirurgias são geralmente feitas através da observação do olho sob cirurgia por um microscópio cirúrgico. Assim, vários ceratômetros acoplados ao 
microscópio cirúrgico foram patenteados, porém, realmente nenhum destes está ativamente no mercado.

O primeiro ceratômetro cirúrgico experimental, chamado de oftalmômetro cirúrgico binocular quantitativo, foi usado pelo cirurgião José Ignácio Barraquer, na Colômbia. Este instrumento consiste na montagem do ceratômetro de Javal-Schiötz em posição vertical e permanece ao lado do microscópio cirúrgico [BARRAQUER, J. I.; 1980].

O ceratômetro cirúrgico quantitativo em uso atualmente, foi projetado por Clifford M. Terry [COLVARD, D.M.; 1981], sua patente foi requerida em 1984 e é comercializado pela Alcon Laboratories Inc. (TX, USA). Este instrumento projeta um círculo iluminado, e este é refletido pelo filme lacrimal da córnea do paciente e emprega um duplo prisma fixo para gerar duas imagens. O tamanho das imagens fornecidas passam por um controle de magnificação de maneira que a mesma coincida com a imagem do campo operatório. Um sistema computadorizado transforma a alteração da magnificação em dioptrias e os dados podem ser armazenados para posterior comparação. O prisma pode ser rotacionado, assim possibilitando a detecção do astigmatismo em todos seus meridianos. O prisma tem que ser retirado do sistema óptico após a realização das medidas para permitir a observação do olho do paciente. 


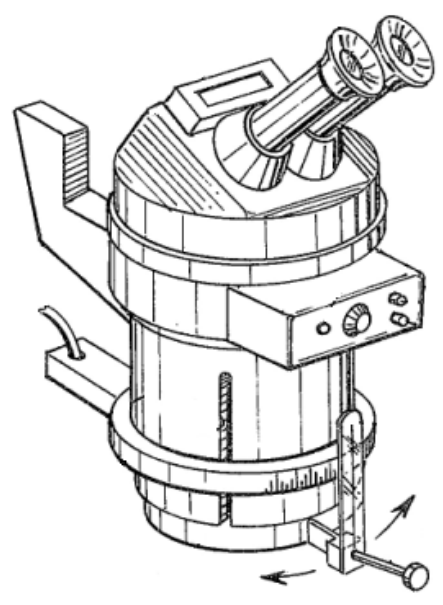

Figura 3.4 Ceratômetro cirúrgico quantitativo de C. M. Terry. [MESAROS, J.; et al, 1984].

Os ceratômetros, até os dias atuais desenvolvidos, sofrem de pelo menos um dos grandes problemas atrelados à sua concepção. Um deles é que é extremamente difícil (utilizando os ceratômetros tradicionais) medir o raio de curvatura da córnea com a precisão desejada. Um outro deles é que uma fonte de luz extra, que não seja a do microscópio, é geralmente necessária para iluminar o alvo de projeção. Esta fonte de luz secundária adiciona custo ao ceratômetro e atrapalha a área de trabalho do cirurgião frequentemente.

Um terceiro fator é a lentidão e complexidade de operação do instrumento, atrapalhando $\mathrm{o}$ campo de trabalho do cirurgião $\mathrm{e}$ consequentemente onerando a cirurgia. Além disto, todos estes fornecem apenas a ceratometria e nenhum dado indicativo de como atingir a circularidade da córnea é proporcionado.

É com o objetivo de superar algumas destas falhas, que o presente trabalho é proposto. 
Capítulo 4

\section{DESENVOLVIMENTO DO SISTEMA}

O primeiro sistema desenvolvido, foi um dispositivo independente do uso do microscópio cirúrgico como parte integrante do sistema.

O dispositivo era composto por uma mira de projeção localizada em uma de suas extremidades, composta por em 16 LEDs vermelhos (2mm de diâmetro cada) dispostos num diâmetro de 11,6mm em um anel de PVC preto. A mira projeta sobre o filme lacrimal do olho do paciente a mira, cujo reflexo da imagem é captada pelo centro do dispositivo que possui uma lente de magnificação de $3 \mathrm{X}$ e uma câmera CMOS (Nativa modelo NSW-205). A imagem disponibilizada pela câmera era enviada a um micro computador, via um cabo USB (pinnacle Linx) e então analisada por um programa desenvolvido para esta finalidade. O dispositivo, a mira observada pelo paciente e as imagens refletidas de uma esfera de aço e do olho do paciente estão apresentados na figura 4.1. A imagem da tela de interface do programa desenvolvido está apresentada na figura 4.2.

Como este dispositivo apresentou vários problemas para alinhamento (não havia um sistema de alinhamento central e tão pouco 
angular), pouca magnificação da imagem, qualidade ruim da imagem, etc, levando à imprecisão do sistema [SAIA, P.; 2006], outros sistemas foram desenvolvidos.
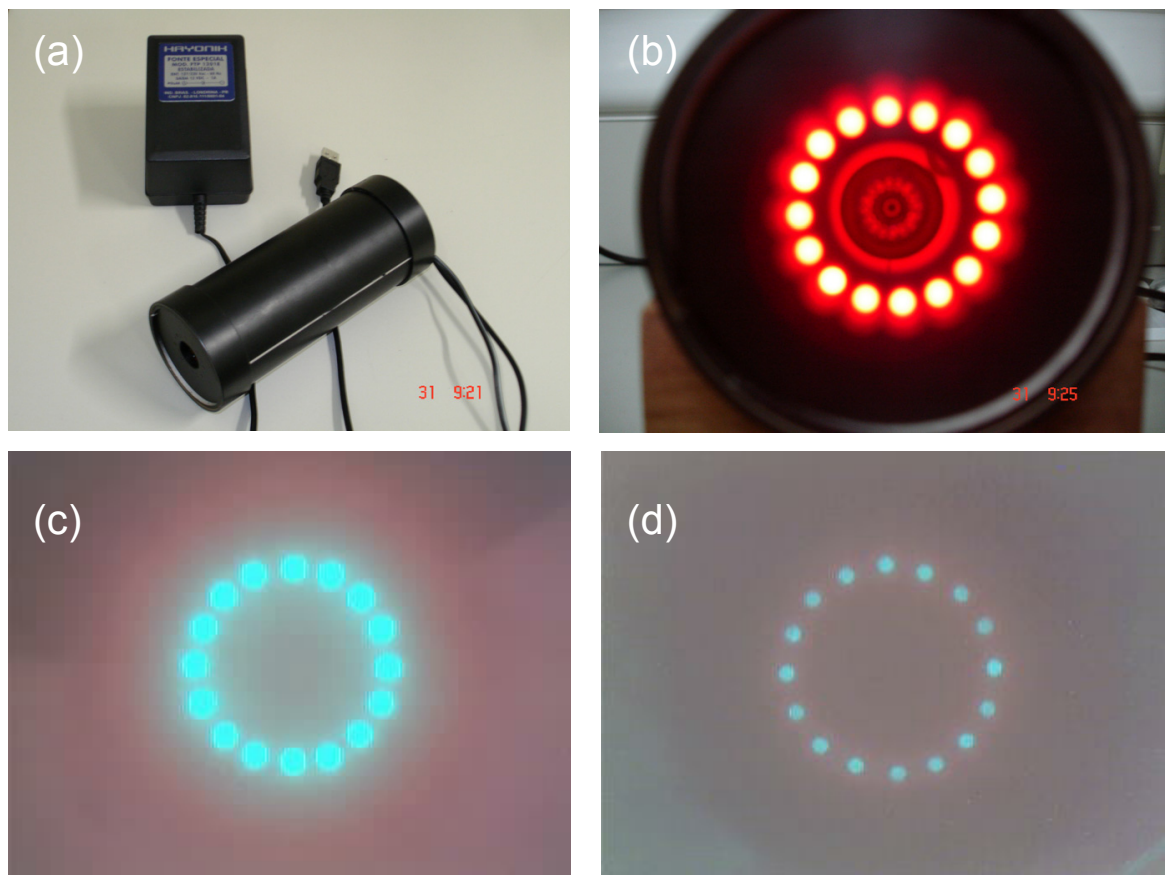

Figura $4.1 \quad$ (a) Dispositivo; (b) mira observada pelo paciente; (c) imagem refletida em uma esfera de aço; (d) imagem refletida do olho do paciente.

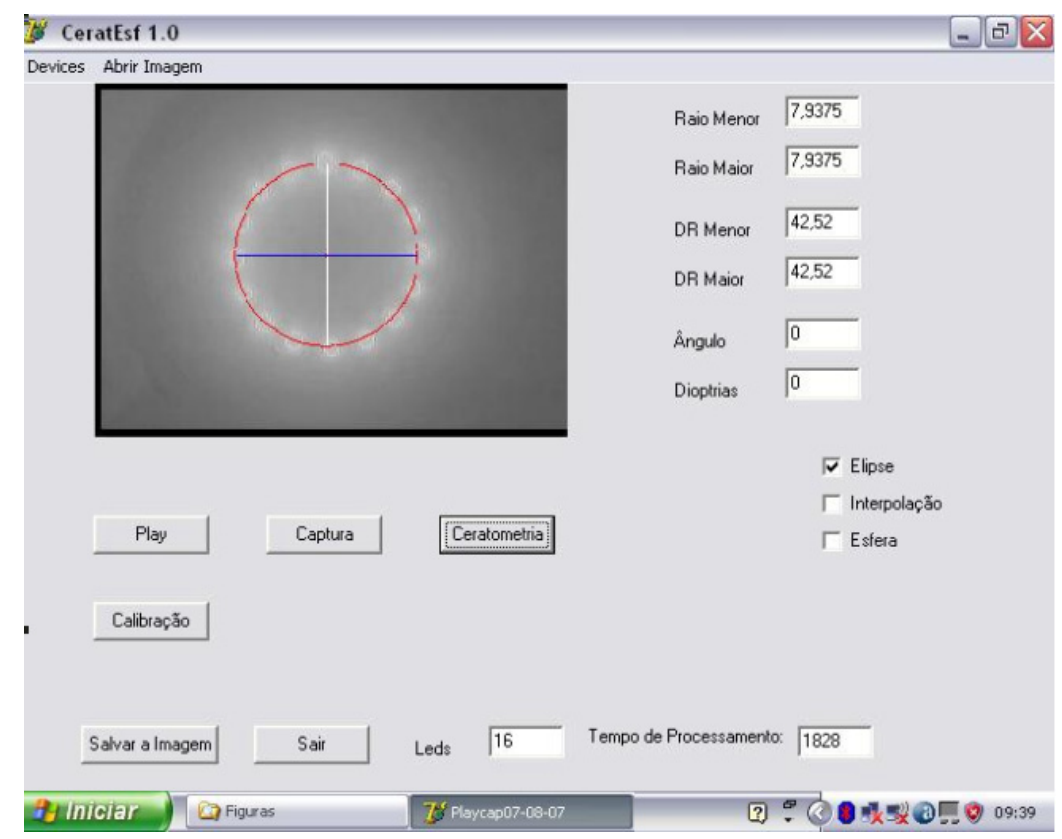

Figura 4.2 Tela de interface do programa ceratométrico desenvolvido. 


\subsection{SEGUNDO SISTEMA DESENVOLVIDO}

O sistema ótico é constituído pela projeção na córnea do paciente de um alvo luminoso circular, posicionado sob a objetiva do microscópio ocular - vide Figura 4.3 - e pela recepção da imagem refletida pelo filme lacrimal deste alvo, para análise. A imagem refletida atinge a objetiva do microscópio ocular e é observada pelas oculares e pelo "carona" - sistema de vídeo comercial adaptado ao microscópio e recebida por uma câmera do CCD (WATEC mod. 221-S). A imagem é enviada a um mini computador (OQO - model 2 -Pentium IV, 1,5 GHz, 2GB RAM e 120GB HD) por um cabo de vídeo USB (Pinnacle Linx) e, então, processada. A deformidade da imagem refletida em relação à imagem projetada fornece o astigmatismo do olho examinado.

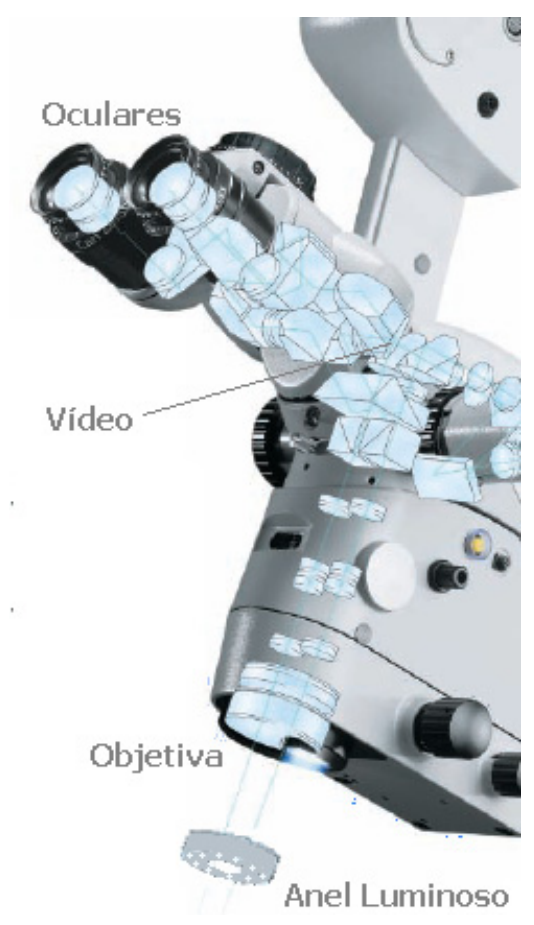

Figura 4.3 Desenho esquemático do microscópio da Carl Zeiss Medtec (parte do desenho acessado em 21/09/2007 em http://www.meditec.zeiss.com) com indicações dos acessórios a serem acoplados para o sistema de apoio à cirurgia. 
O anel luminoso, mira de projeção para o microscópio cirúrgico, é constituído por pontos luminosos alojados em um disco de PVC preto.

Vários protótipos foram construídos no intuito de se unir precisão de medida com viabilidade clínica.

Os alvos desenvolvidos foram basicamente de dois tipos: anel com LEDs e furos preenchidos por capilares de vidro.

\subsubsection{O Alvo de Capilares}

O alvo de capilares é acoplado em um sistema de lentes comercial (adaptador de vídeo APRAMED para lâmpada de fenda do tipo Haag-Streit) e utilizado manualmente durante o processo cirúrgico.

A figura 4.4a mostra a foto do anel, que é iluminado pela lâmpada do microscópio cirúrgico ocular; e a figura 4.4b mostra o anel acoplado ao adaptador de vídeo de Lâmpada de Fenda do tipo Haag-Streit da APRAMED, que possui magnificação da imagem de $6 \mathrm{X}$.

O alvo é constituído por 36 capilares de vidro polidos, de $10 \mathrm{~mm}$ de comprimento e $5 \mathrm{~mm}$ de diâmetro e possui um diâmetro de disposição dos capilares de $45 \mathrm{~mm}$. Nove fibras óticas, de diâmetro de 1,5mm foram dispostas a cada $90^{\circ}$, agrupadas em três seqüencialmente, para o alinhamento da câmera com o olho a ser examinado. Este conjunto de fibras óticas será denominado de mira de alinhamento ótico. A luz do microscópio ocular ilumina o alvo e a mira de alinhamento ótico, apresentando a imagem mostrada na figura 4.5. 
A imagem refletida da córnea é pequena (6X de magnificação), comprometendo a precisão do programa já existente para ceratometria, porém não o inviabilizando. Um sistema ótico de maior magnificação deve ser acoplado ao sistema para que uma imagem de aumento de pelo menos $10 \mathrm{X}$ possa ser obtida.

Apesar de o sistema manual ter a vantagem de poder ser utilizado também fora de campo cirúrgico, como um ceratômetro regular, apenas trocando o anel de capilares por um anel de LEDs, ele é um sistema relativamente pesado para ser utilizado em campo cirúrgico, uma vez que não pode encostar ao redor do olho do paciente, como no ceratômetro manual regular, para se obter uma maior estabilidade na focalização e centralização.
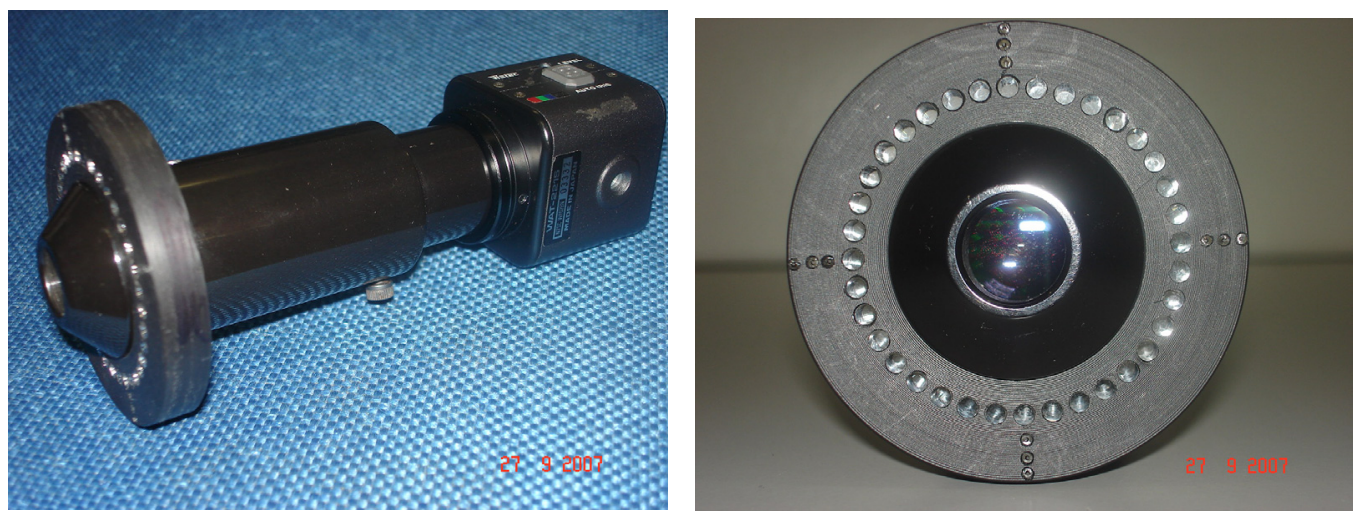

Figura 4.4 (a) Anel acoplado ao adaptador de vídeo da APRAMED $^{\circledR}$ (b). Foto frontal do anel de capilares de vidro e mira de alinhamento ótico.

Desta forma a idéia de se utilizar um sistema ótico adicional ao microscópio cirúrgico foi abandonada e a ótica de recepção da imagem refletida da córnea a ser utilizada passou a ser a do próprio microscópio cirúrgico, bem como o adaptador de vídeo comercial para microscópios oculares. 


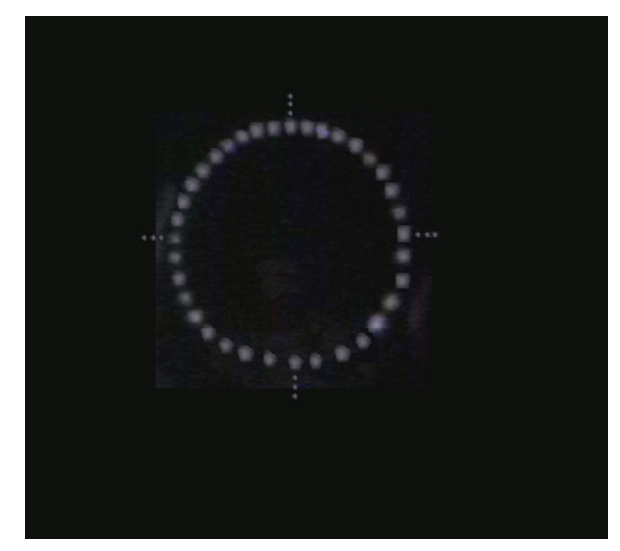

Figura 4.5 Imagem do alvo projetada numa córnea de voluntário, apresentada pelo sistema da fig. 4.2.

Assim, uma mira de anel com LEDs foi construída. A mira de capilares foi retirada do sistema, pois a luz que agora passa pelo eixo central, uma vez que o adaptador de vídeo não mais está ali posicionado, causa problemas no processamento da imagem, interferindo no resultado final.

\subsection{TERCEIRO SISTEMA DESENVOLVIDO}

O anel é composto por 36 LEDs fixados numa placa de cobre e então encaixados num invólucro de nylon preto, como mostra o desenho da figura 4.6. 


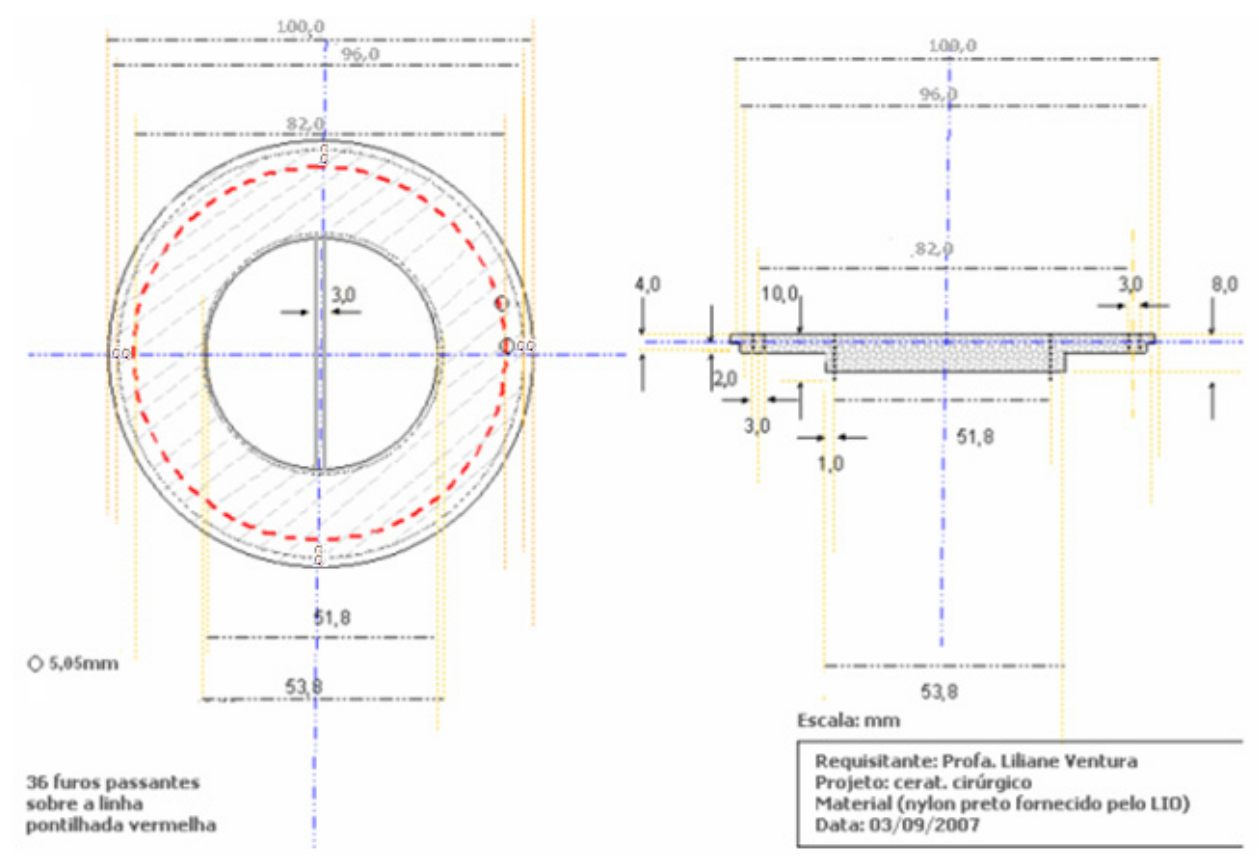

Figura 4.6 Projeto do invólucro de nylon preto que aloja o anel com 36 LEDs.

Foi feita uma placa de circuito impresso em formato circular, como pode ser visto na figura 4.7, para ser alojada dentro do invólucro de nylon.

Cinco modelos diferentes de mira foram projetados e confeccionados, diferenciando-se pela dimensão do anel, pela quantidade de LEDs envolvidos (48 LEDs, a cada $7,5^{\circ}$ ou 36 LEDs a cada $10^{\circ}$ ), com sistema para a centralização com o olho do paciente, dimensão e profundidade dos furos para encaixe dos LEDs (os LEDs não podem borrar ou distorcer a imagem em função da não homogeneidade de potência de iluminação entre eles, ou seja, LEDs mais brilhantes do que os outros, com ângulo de iluminação ligeiramente diferente - os LEDs possuem um cone de iluminação de $60^{\circ}$ em média devem ficar posicionados de forma a não interferir na imagem e, portanto, na ceratometria), escolha mais adequada de tipos de LEDs (amarelos, de alto brilho, vermelhos, infravermelhos, de diâmetros variados, etc) e eletrônica compatível para poder confeccionar um anel delgado. 

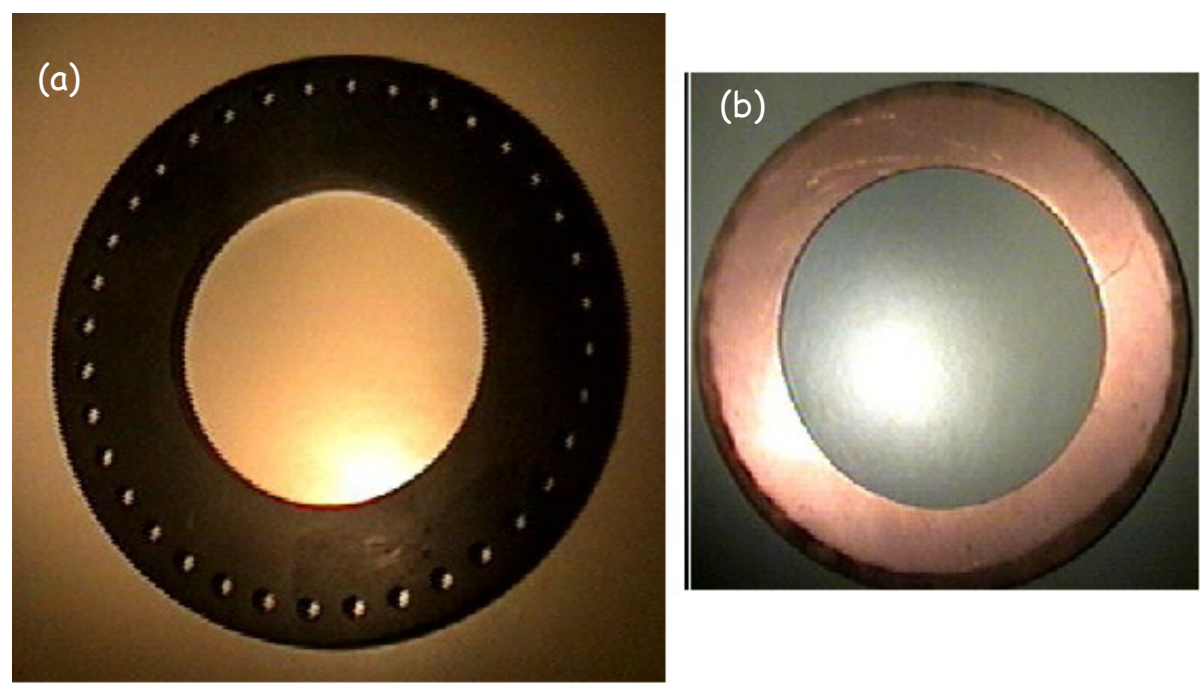

Figura 4.7 Fotos dos: (a) anel de PVC preto, (b) placa do circuito impresso.

Os LEDs vermelhos, que melhor sensibilizam o CCD, mesmo os de alta intensidade, não tinham potência suficiente para iluminar o olho e serem observados pelo sistema ótico, uma vez que a distância entre a imagem refletida pelo olho e a objetiva do sistema é de $200 \mathrm{~mm}$, fazendo com que a luminosidade que atinge o CCD seja muito pequena.

Foi necessário que a câmera utilizada fosse do tipo CCD neste caso, pois apresentava melhor resolução para baixas intensidades de luz.

O anel possui 36LEDs, "luz do dia" de alto brilho, com 1000 lumens de intensidade, $5 \mathrm{~mm}$ de diâmetro, com cone de abertura aproximadamente de $120^{\circ}$, posicionados a cada $10^{\circ}, 1 \mathrm{LED}$ vermelho de $3 \mathrm{~mm}$ central, para realizar a centralização do olho e quatro outros LEDs, a cada $90^{\circ}$, para alinhamento angular do sistema com o olho do paciente e com o microscópio cirúrgico, através das orientações na interface do programa, que será discutido no próximo capítulo. 
A Figura 4.8 mostra a foto do anel de LEDs com um cabo confeccionado em alumínio, para o usuário segurá-lo. Este número de LEDs garante a precisão de $1^{\circ}$ no eixo do astigmatismo, quando o software interpola a melhor elipse para o astigmatismo, uma vez que o sistema de vídeo (cabo de transferência de imagem e câmera CCD) garante a precisão de 0,08mm no raio de curvatura medido. Um número menor de LEDs não garante esta precisão no eixo do astigmatismo.

Obviamente que, anel com maior número de LEDs proporciona precisão maior, porém, não necessária neste caso.

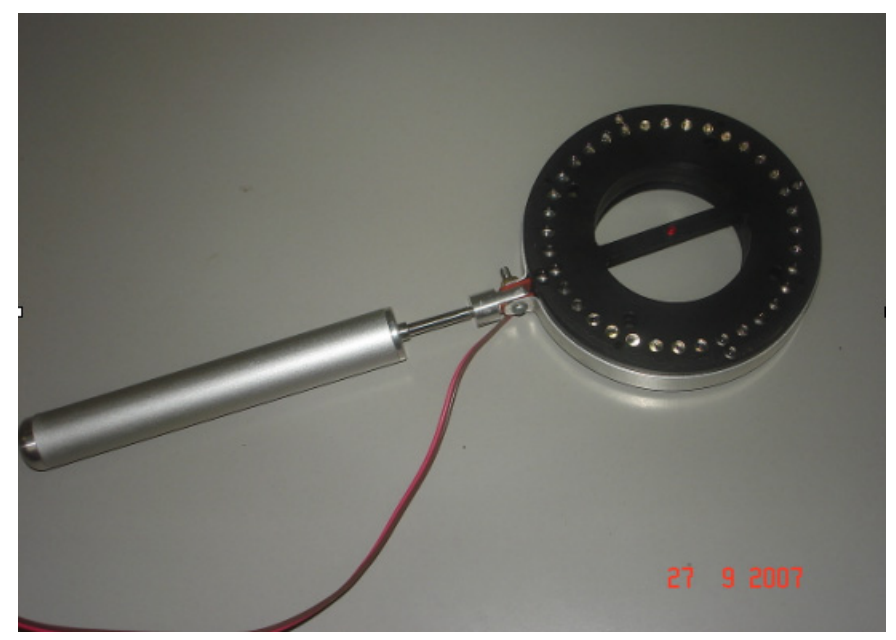

Figura 4.8 Anel composto por 36 LEDs brancos do tipo "luz do dia".

O circuito eletrônico é composto pelos 36 LEDs ligados em paralelo (tensão em cada LED de $5 \mathrm{~V}$ e corrente de 50mA).

Um potenciômetro $(1 \mathrm{k} \Omega$ por $5 \mathrm{~W})$ foi adicionado ao circuito para que a luz emitida pelos LEDs possa ter a intensidade controlada para testes.

A figura 4.9a mostra o sistema como um todo e a figura $4.9 \mathrm{~b}$ mostra a imagem de como o anel é utilizado em campo cirúrgico. Como a autorização do 
conselho de ética da Faculdade de Medicina de Ribeirão Preto ainda não está liberada, a foto é apenas uma simulação da medida. O anel permaneceu desligado durante a foto e a paciente autorizou sua imagem para ser utilizada, uma vez que sua face não está descoberta.

A figura 4.10 ilustra a imagem refletida da projeção do anel numa esfera de aço inox e num olho de uma voluntária do Laboratório de Instrumentação Oftálmica - EESC/USP.
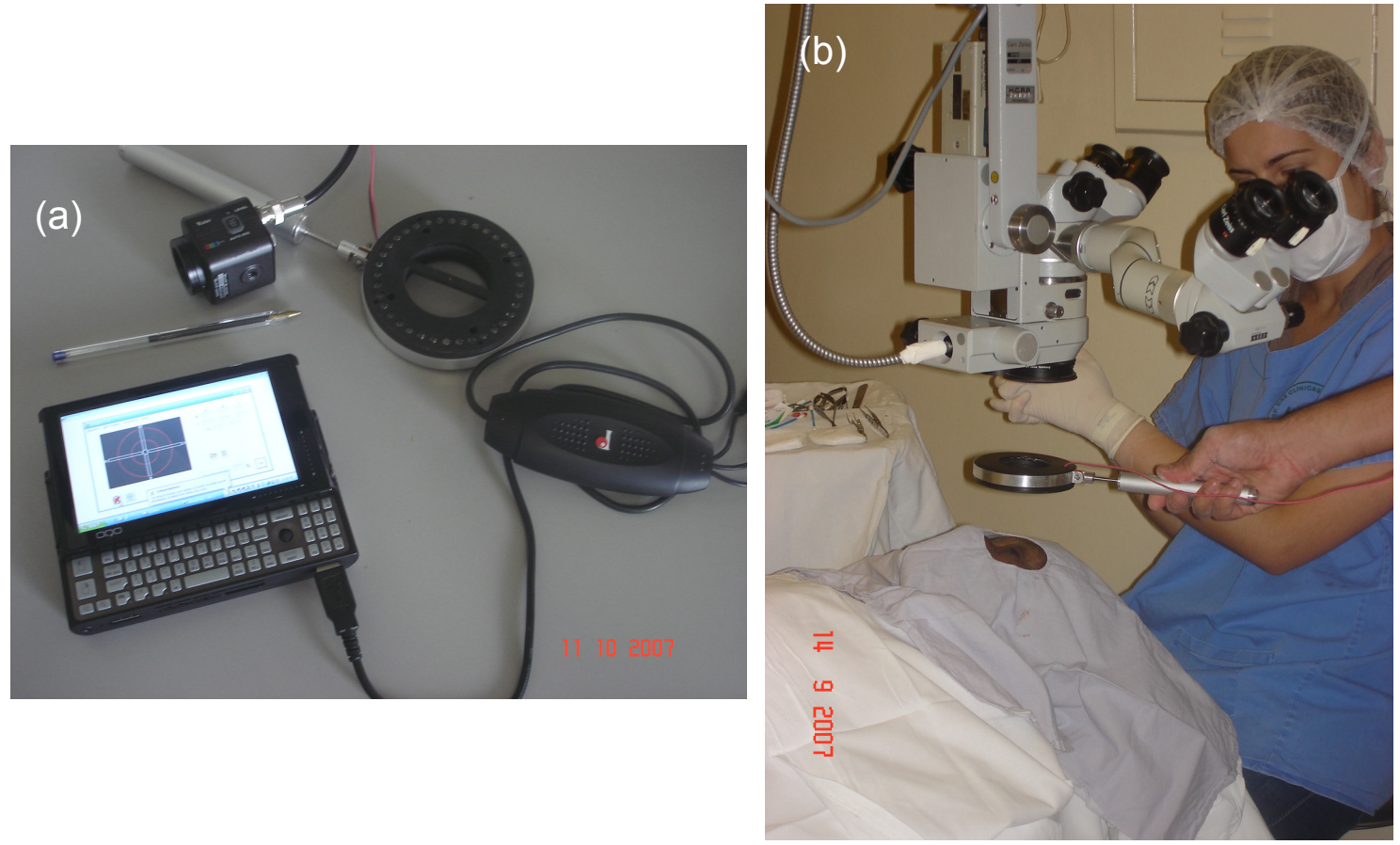

Figura 4.9 Fotos: (a) Dispositivos do sistema para apoio cirúrgico; (b) Simulação da medida em campo cirúrgico. 

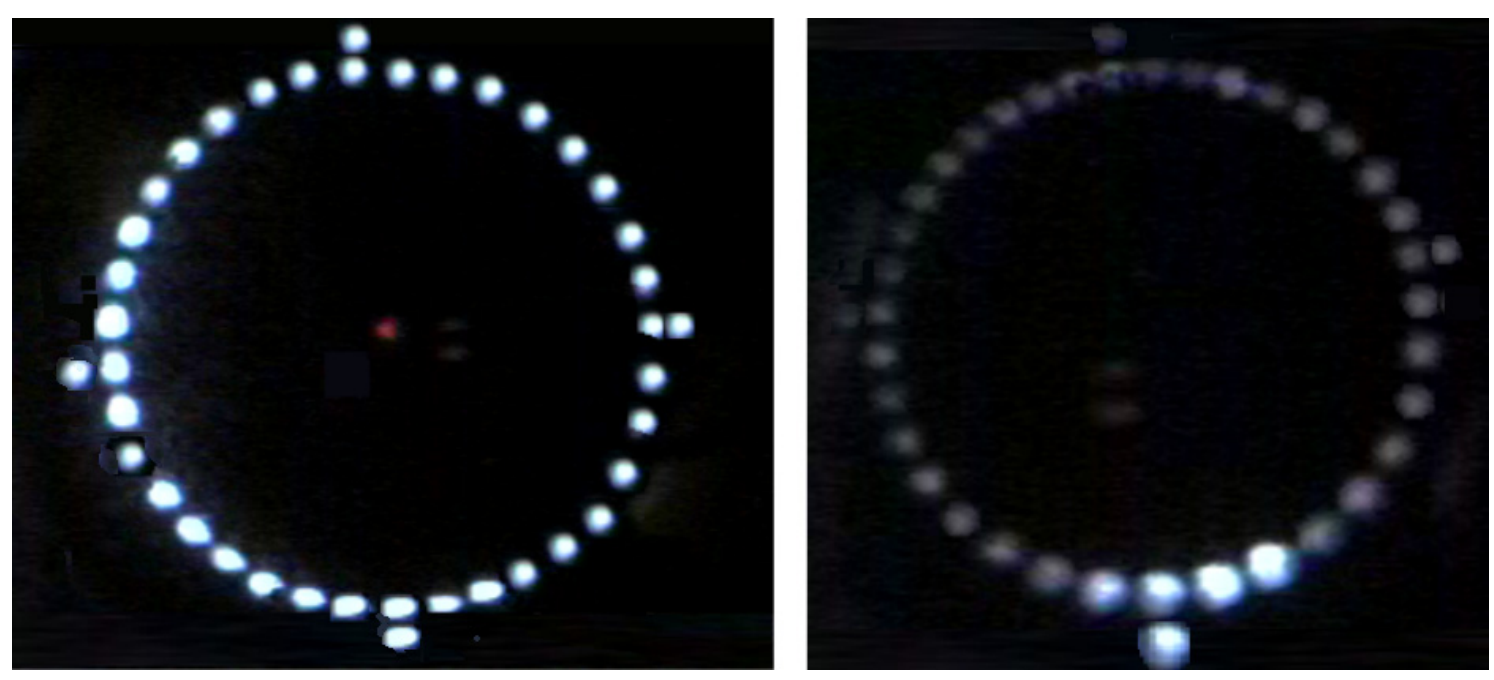

Figura 4.10 Imagem refletida da projeção do anel em: (a) esfera de aço inox; (b) olho de uma voluntária do Laboratório de Instrumentação Oftálmica - EESC/USP.

As imagens da figura 4.10 são as imagens ativas do sistema, ou seja, apresentadas em tempo real. As imagens quando capturadas não possuem os LEDs de centralizações linear e angular, pois eles são desligados por um circuito quando o botão de captura do programa é acionado [VENTURA, L.; 2007]. 
Capítulo 5

\section{O PROGRAMA DESENVOLVIDO}

O programa desenvolvido para o sistema de apoio à sutura ocular consiste de três partes fundamentais:

1. Processamento da imagem: os pontos de luz projetados no olho e que são refletidos, devem ser identificados. Apenas os pontos pertencentes ao reflexo do anel devem ser identificados. Os LEDs de alinhamentos central e angular, do alvo luminoso, são desligados no momento da captura (já para o anel de capilares, os pontos de alinhamento são desprezados no programa, uma vez que estão fora da região de análise, como será mostrado mais adiante). Uma vez identificados os pontos, uma linha traçada sobre eles é apresentada visualmente, para que o clínico possa ter noção onde os pontos da sutura devem ser apertados ou relaxados;

2. Determinação da Ceratometria: os pontos identificados devem ser interpolados e a melhor elipse ajustada aos pontos para o fornecimento da ceratometria;

3. Determinação da Circularidade: esta função é matematicamente conhecida por excentricidade, e, neste caso, tem o objetivo de mostrar 
ao clínico, em porcentagem, o quanto a região central da córnea está distante de um círculo ideal. Desta forma, o clínico pode ter uma indicação quantitativa da sutura;

4. Programa de interface com o usuário;

5. Programa para calibração.

\subsection{O PROGRAMA DE PROCESSAMENTO DA IMAGEM}

A imagem a ser processada consiste de 36 pontos de luz posicionados de forma circular. O programa de processamento da imagem, bem como o da determinação da ceratometria é o mesmo utilizado para o ceratômetro em Lâmpada de Fenda, apenas com a dimensão de máscara e fator de corte diferentes [VENTURA, L., et al 2006].

Como as intensidades dos pontos de luz não são homogeneamente distribuídas, um processo de convolução é realizado, ao empregar uma máscara circular com um raio do tamanho do raio médio da distribuição dos pontos de luz, desta forma, identifica-se a posição da imagem dos LEDs.

Ao percorrer a imagem com esta máscara, a imagem do LED de maior intensidade é primeiramente identificada [VENTURA, L.; 2007].

O centro de massa com posição bem definida, é identificado e sua posição é armazenada como $(P x[1], P y[1])$. Ao proceder de forma recursiva, as estruturas com intensidades mais baixas são identificadas. 
Quando as estruturas $N_{e}$ (os LEDs) são identificadas, bem como a posição de seus respectivos centros de massa $(P x[i], P y),\left(x_{c m 0}, y_{c m 0}\right)$ pode ser determinado, o que define a posição do centro da imagem por:

$$
x_{c m 0}=\sum \frac{P x[i]}{N_{e} e y_{c m 0}}=\sum \frac{P y[i]}{N_{e}}
$$

Obtém-se, então, uma curva interpolada a partir da posição do centro de massa da imagem refletida da mira.

\subsection{O PROGRAMA DE DETERMINAÇÃO DA CERATOMETRIA}

A função utilizada para representar a imagem refletida da mira é uma elipse, e esta possui um ângulo de inclinação $\theta$ com relação ao eixo das abscissas.

Determina-se, agora, a melhor curva elíptica que se ajuste a imagem da mira refletida. O ajuste é realizado ao empregar os pontos interpolados determinados no processamento da imagem.

Estes pontos foram definidos em coordenadas polares para ângulos $\Theta_{i}=n_{i} \Theta_{0}$ em graus, onde $0^{\circ} \leq \Theta_{i} \leq 360^{\circ}$. Para se obter a precisão adequada no ajuste da melhor elipse, escolheu-se $\Theta_{0}=1^{\circ}$ e $n_{i}=0,1,2,3, \ldots, 359$. 
A elipse com centro coincidente ao centro de massa da imagem é dada por:

$$
\frac{x^{2}}{a^{2}}+\frac{y^{2}}{b^{2}}=1
$$

onde, a e b são os raios menor e maior da elipse, e x e y são as coordenadas.

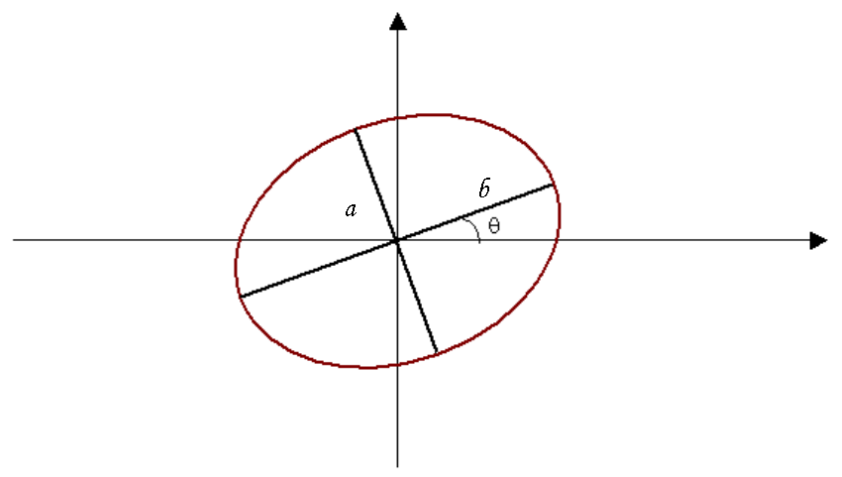

Figura 5.1 Representação da elipse determinada no algoritmo, melhor ajustada às imagens dos LEDs.

A melhor elipse é determinada a partir de uma elipse de teste com ângulo de inclinação $\theta=n_{i} \Theta_{0}$, onde $0^{\circ} \leq n_{i} \leq 90^{\circ}$. Para cada valor de $n_{i}$, calculase o desvio médio quadrático entre os pontos interpolados com os pontos definidos pela elipse determinada pela interpolação da curva mediana do anel. O desvio médio quadrático é, então, dado por:

$$
S=\sum_{i=0}^{359}\left(r_{i}-r\right)^{2}
$$


onde $r_{i}$ é o valor do raio obtido pela curva ajustada (em função de $\Theta_{i}$ ) e $r$ é o raio da curva da elipse de interpolação da curva mediana do anel, definido pela transformação $(P x[i], P y[i]) \rightarrow(r[i], \Theta[i])$, ou seja, $x=r \cos \left(\Theta_{i}\right)$ e $y=r \operatorname{sen}\left(\Theta_{i}\right)$.

Para determinar a elipse que melhor se ajusta à imagem, escolhe-se a fórmula da elipse com menor valor de $S$. A conversão de pixels para milímetros é necessária para se apresentar os dados em raios de curvatura.

Os resultados ceratométricos são geralmente apresentados em "poder de refração" $(F)$, dado pela expressão (5.4) e a unidade é expressa em dioptrias (D).

$$
F=\frac{n_{c}-1}{r}
$$

onde, $n_{c}$ é o índice de refração da córnea $\left(n_{c}=1,3375\right)$.

A equação paraxial (5.4) fornece o poder de refração da superfície corneana para os feixes que incidem aproximadamente normais à córnea e é válida apenas para a sua zona central.

\subsection{FUNÇÃO CIRCULARIDADE}

A função de circularidade adicionada ao programa tem o objetivo de mostrar ao clínico, em porcentagem, o quanto a região central da córnea está 
distante de um círculo ideal. Matematicamente, esta função é conhecida como excentricidade.

\section{EXCENTRICIDADE}

Em matemática, excentricidade é um parâmetro associado a qualquer seção cônica.

Pode-se imaginar como se fosse uma medida do quanto uma seção cônica desvia-se de ser circular. Em particular a excentricidade de:

- um círculo é ZERO;

- uma elipse é maior do que ZERO e menor do que UM;

- uma parábola é 1 ;

- uma hipérbole, maior do que 1 e menor do que INFINITO;

- uma semi-reta é 1 ou INFINITO, dependendo da definição utilizada.

A excentricidade é dada por [Steinbruch, A., et al; 1987]:

$$
e=\sqrt{1-k \frac{b^{2}}{a^{2}}}
$$

onde, $b$ é o comprimento do semi-eixo maior, a o comprimento do semi-eixo menor da seção e $\mathrm{K}=1$ para a elipse $(0$ para a parábola e -1 para a hipérbole). 
A figura 5.2 ilustra várias seções cônicas com excentricidades diferentes.

Note que à medida que a excentricidade aumenta, a curvatura decresce.

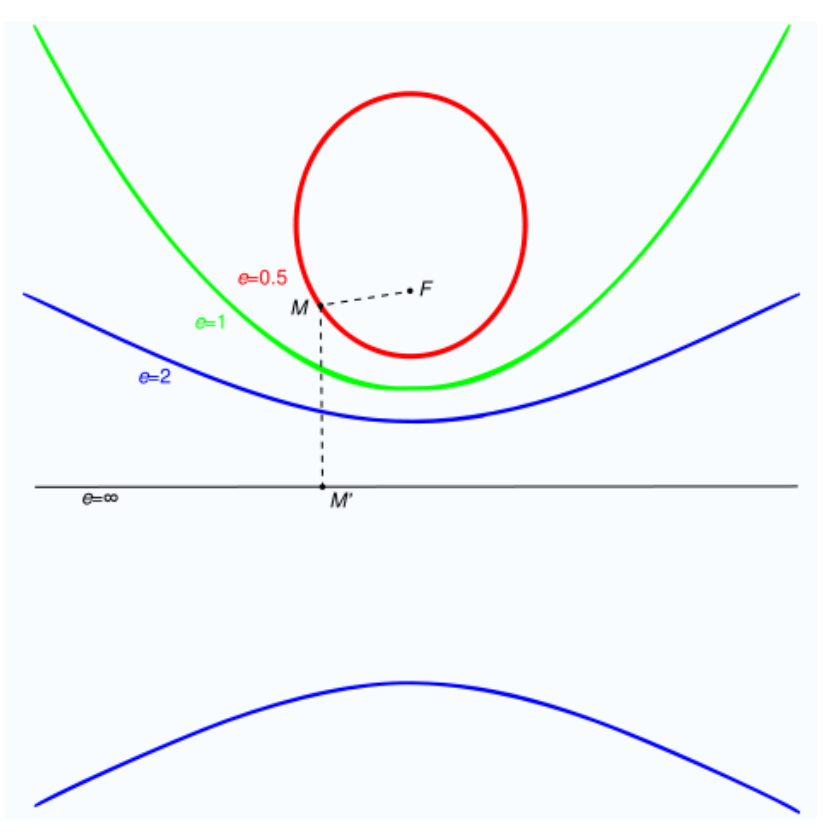

Figura 5.2 Seções cônicas com excentricidades diferentes

(http://pt.wikipedia.org/wiki/Excentricidade - acessado em 29/09/2007).

Assim, a circularidade $C$ foi definida como:

$$
C=100(1-e)
$$

dado em porcentagem. 
Note que para a elipse $0<e<1$, de forma que a circularidade varia entre $0 \%-100 \%$.

\subsection{O PROGRAMA DE INTERFACE}

O programa de interface para o usuário sofreu inúmeras alterações à medida que estava sendo testado no Hospital das Clínicas de Ribeirão Preto. A versão final do software está apresentada nas figuras a seguir. A tela de exame do programa (apresentada na figura 5.3) é de fácil interação e intuitiva.

Quando o programa é acionado, a imagem é disponibilizada em tempo real. Há uma mira para a centralização do sistema com o olho a ser examinado, que indica o alinhamento do olho do paciente.

A parte indicada por 1 na figura 5.3 é uma mira central para garantir o alinhamento coaxial do olho do paciente com o microscópio cirúrgico. A indicada por 2 são as miras de alinhamento angular da câmera CCD com o olho do paciente e com o microscópio cirúrgico. As imagens dos LEDs posicionados a cada $90^{\circ}$ devem estar coincidentes com estas marcações ortogonais. O 3 indica a região onde a imagem deve estar localizada para minimizar erros na ceratometria e na obtenção da circularidade. O ponto vermelho de fixação central deve estar coincidente com o centro deste quadrado e os 36 pontos de luz em foco, para que a imagem possa ser capturada, através do mouse, ou botão de mão, ou pedal, disponíveis no sistema. 
Os comandos existentes na tela, representada na figura 5.3, estão expostos a seguir.

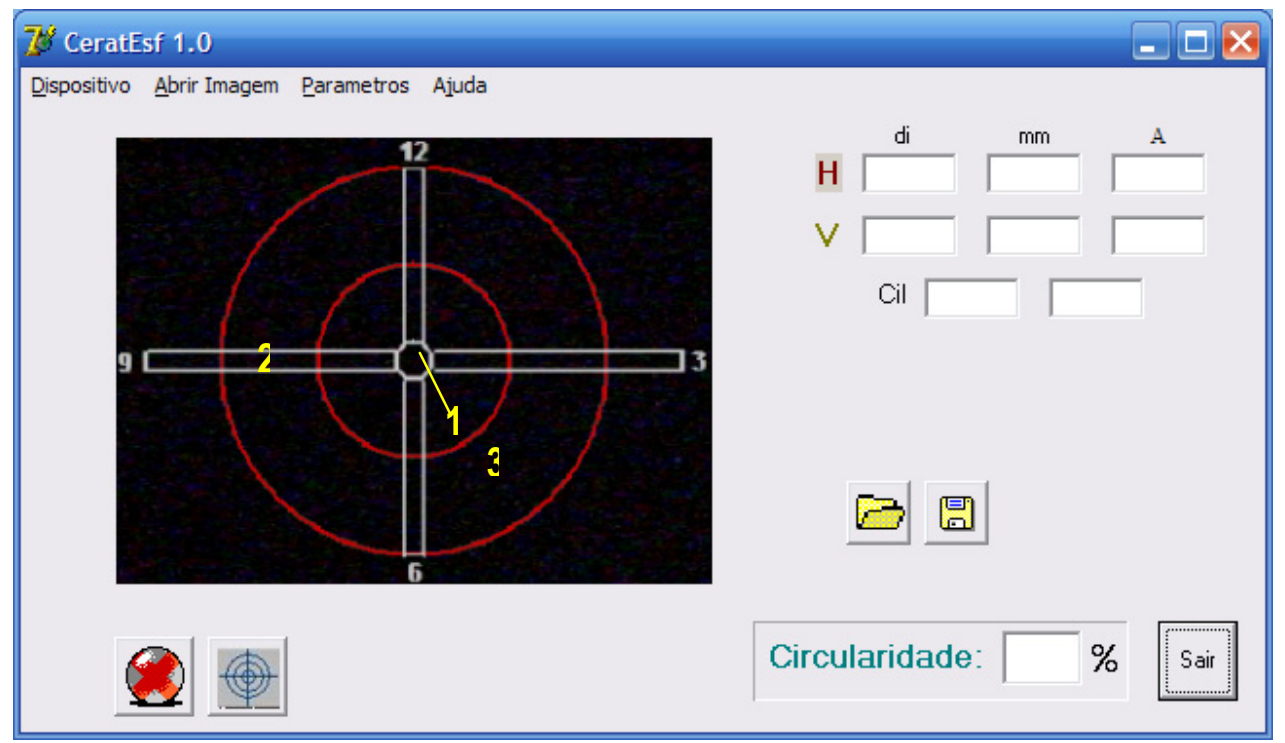

Figura 5.3 Tela de apresentação durante a focalização da mira na córnea do paciente.

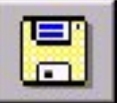

SÍMBOLO DE DISQUETE: este comando serve para armazenar os exames realizados no HD do computador associado ao ceratômetro.

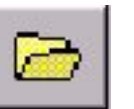

SÍMBOLO DE ABRIR ARQUIVO: este comando serve para restaurar na tela um arquivo armazenado anteriormente. A medida apresentada, quando uma imagem é aberta, é a correspondente com a calibração atual do equipamento.

SÍMBOLO DE UMA BOLA COM UMA CRUZ: este comando serve para acionar a captura da imagem e, portanto, realizar o exame. Esta cruz vermelha torna-se azul ao realizar aos exames. 
SÍMBOLO DE CALIBRAÇÃO: este comando tem a função de calibrar o sistema. É prudente que todo início de cirurgia o sistema seja calibrado.

\subsection{PROGRAMA DE CALIBRAÇÃO}

Para a calibração, uma esfera de aço inox de precisão é posicionada sobre um dispositivo, como mostra a figura 5.4. A câmera CCD é previamente alinhada com um dispositivo em forma de cruz, posicionado na mesa do paciente, de forma a se alinhar com as miras de alinhamento angular do sistema.

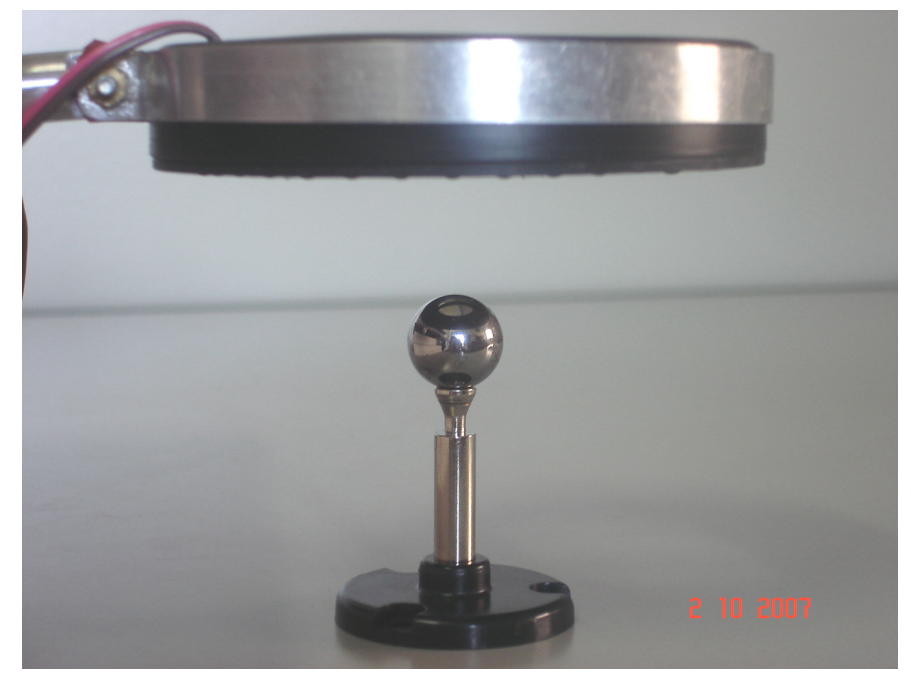

Figura 5.4 Dispositivo de calibração do sistema. 
Quando o botão de calibração é acionado, a imagem da esfera de aço inox, focalizada e centralizada, cujo raio de curvatura é de $7,859 \mathrm{~mm}$ $\pm 0,0025 \mathrm{~mm}$, deve ser obtida. Um aviso de CALIBRAÇÃO EM ANDAMENTO (figura 5.5a) é mostrado e, assim que concluído, o sistema mostra o aviso de CALIBRADO - figura 5.5b.

Neste momento, o que ocorre é que no ajuste da melhor elipse que pode ser traçada nos pontos da imagem, aos raios de maior e menor curvatura (ou poder de refração) são atribuídos os valores de 7,859mm.

O resultado da ceratometria é apresentado no modo convencional ( $\mathrm{V}=$ vertical; $\mathbf{H}=$ meridiano horizontal, ou seja, meridiano que está entre $\geq 0 \mathrm{e}$ $<90^{\circ}$ ), com os raios de curvatura e poderes de refração, bem como o astigmatismo (diferença entre os poderes de refração dos dois meridianos, no eixo em que o poder de refração é maior em módulo).

A figura 5.6 ilustra a tela dos resultados apresentados: imagem capturada, ceratometria e circularidade.

Pode-se notar nesta figura, que para quase 1D de astigmatismo a circularidade é de $98 \%$, ou seja, a dificuldade em se suturar uma córnea para que não haja astigmatismo residual devido à sutura é enorme, como poderá ser observado nos resultados a seguir. 

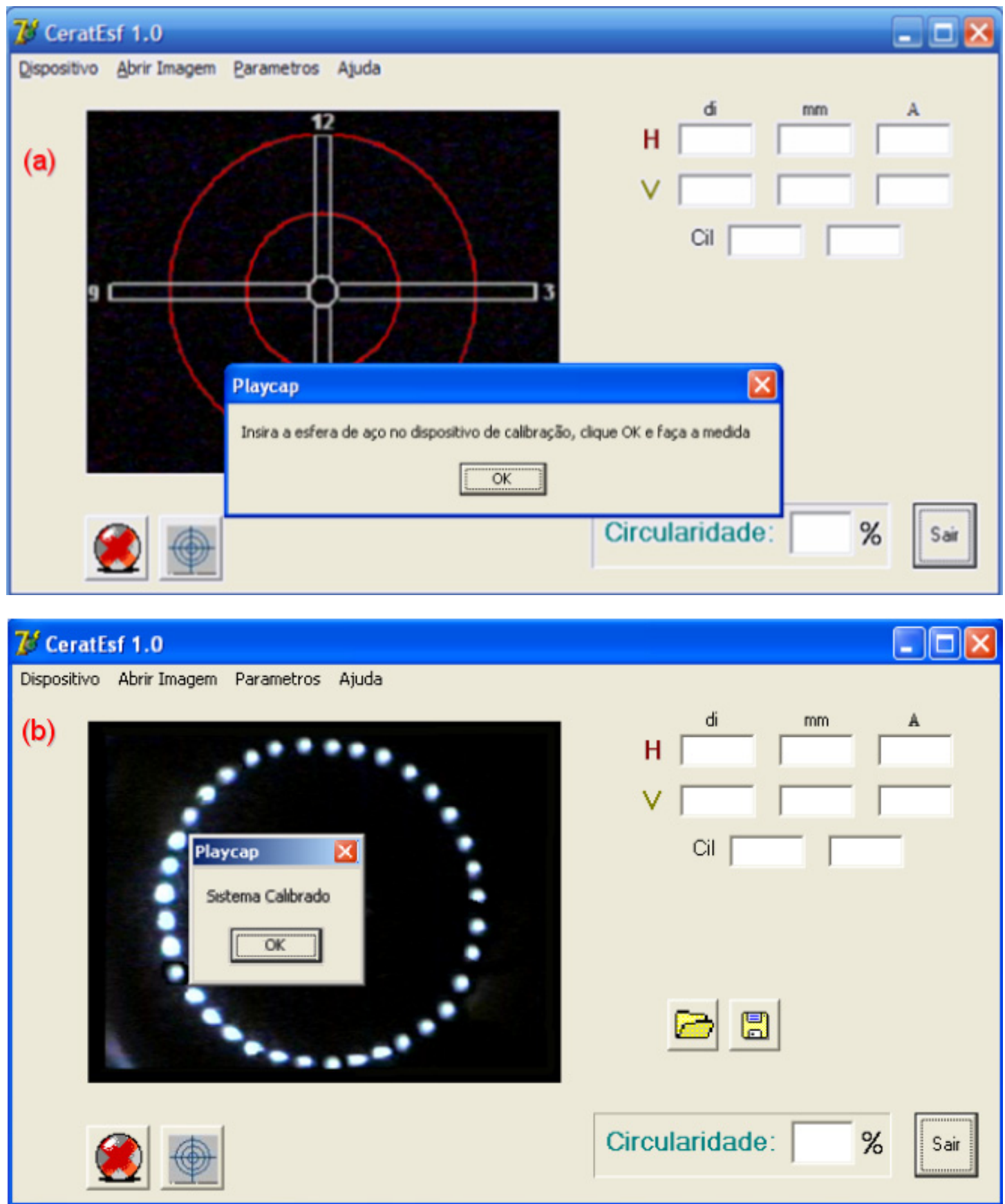

Figura 5.5 Telas de Calibração do sistema: (a) Calibração em andamento; (b) sistema calibrado. 


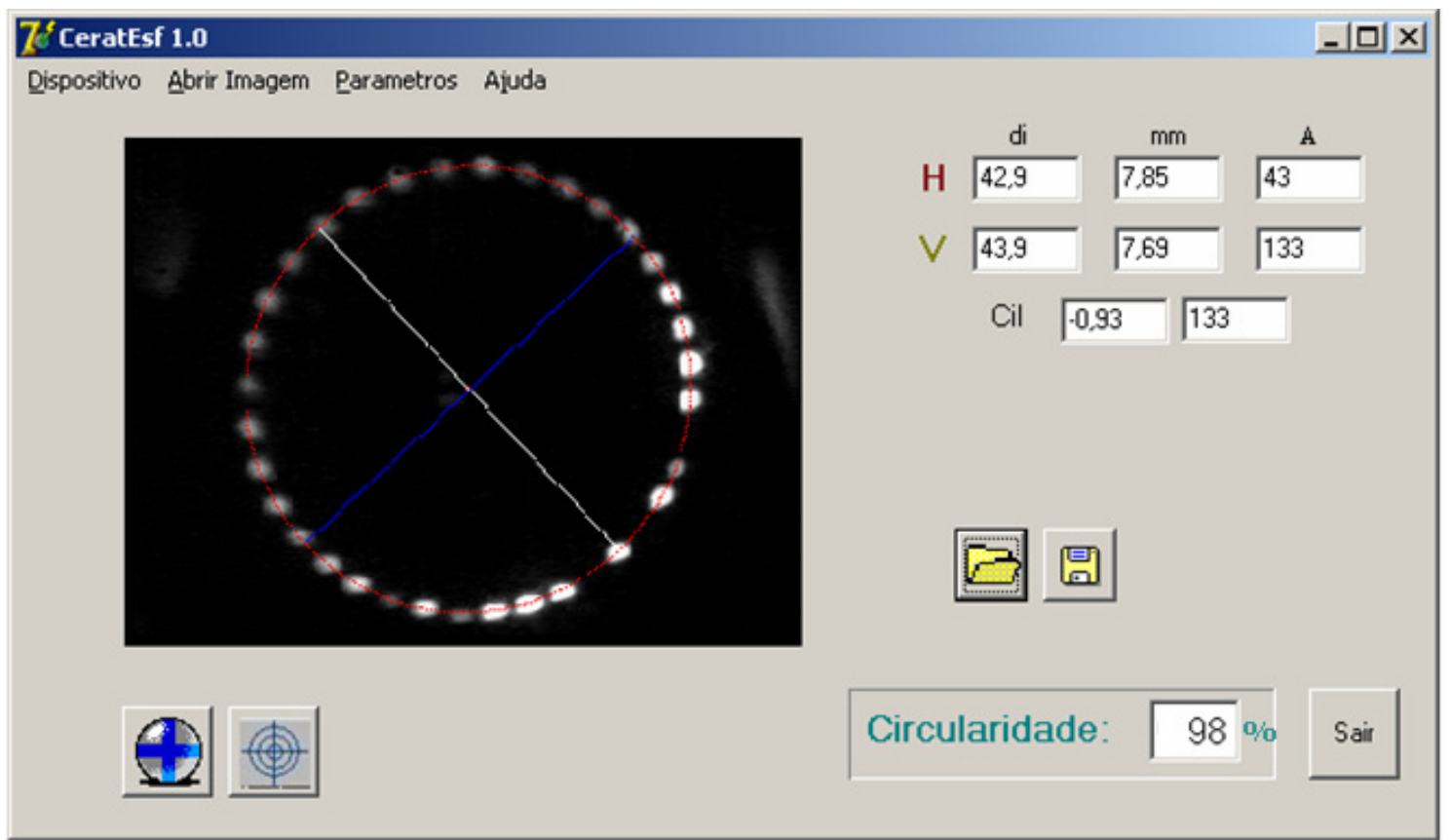

Figura 5.6 Tela dos resultados apresentados: imagem capturada, ceratometria e circularidade. 
Capítulo 6

RESULTADOS

\subsection{AVALIAÇÃO DAS PRECISÕES E REPETIBILIDADE DO SISTEMA}

Para que o sistema pudesse ser utilizado em olhos "in vivo" de voluntários, averiguaram-se a precisão e repetibilidade do sistema em 21 esferas de aço de precisão, de diâmetros variáveis entre 3,0000mm 17,0000mm $\pm 0,0025 \mathrm{~mm}$, de modo a simular os diâmetros reais e diâmetros extremos de uma córnea humana.

A figura 6.1 ilustra o gráfico dos raios de curvatura medidos das 21 esferas em nosso sistema e comparadas aos valores fornecidos pelo fabricante.

Cada medida foi realizada 5 vezes. A cada vez, o anel luminoso era retirado e novamente alinhado e focalizado. A repetibilidade foi de $90 \%$ para as esferas com raios de curvatura em torno de $7,8 \mathrm{~mm}$ (raio de curvatura do modelo ideal de córnea), como mostra a Tabela 6.1, para 13 esferas. Para raios de curvatura maiores foi de $95 \%$ e para raios de curvatura menores, próximos a $2 \mathrm{~mm}$, foi de $87 \%$, devido às críticas centralização e alinhamentos. 


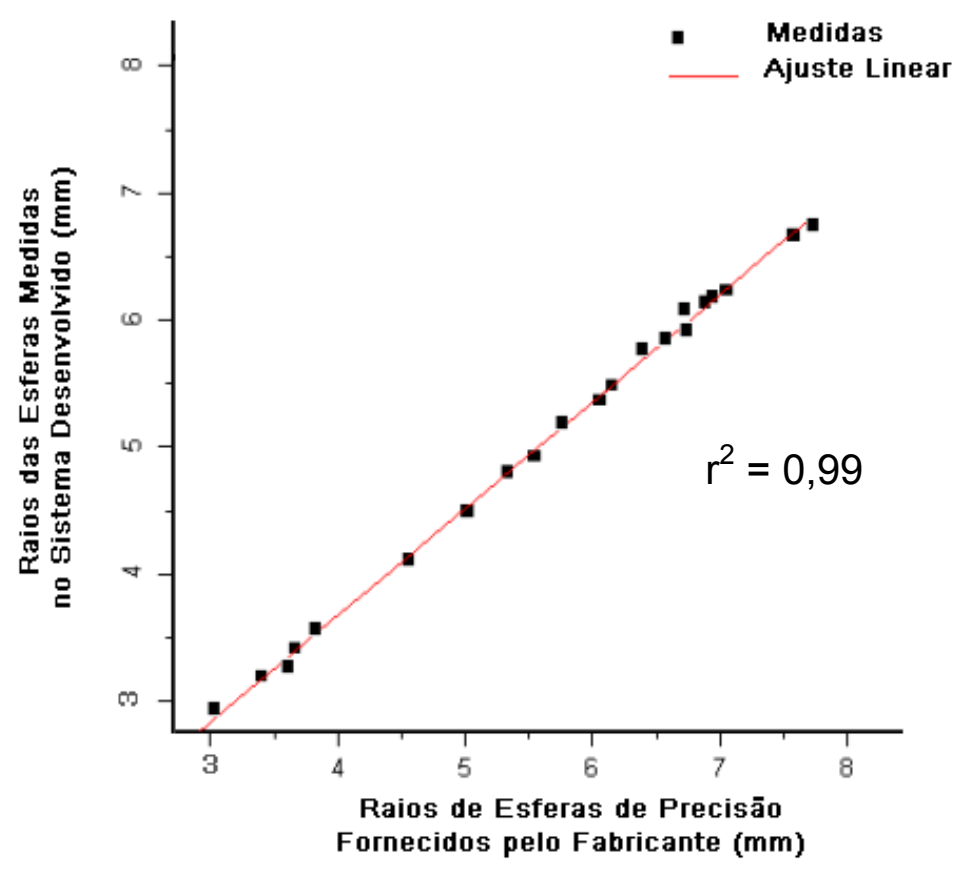

Figura 6.1 Gráfico dos raios de curvatura medidos das 21 esferas em nosso sistema e comparadas aos valores fornecidos pelo fabricante.

Tabela 6.1 Repetibilidade de Medidas dos Raios de Curvatura de Esferas de Precisão

\begin{tabular}{llllllllllllllll}
\hline Dados do & & & & & & & & & & & & & \\
Fabricante & $\mathbf{3 , 0 0}$ & $\mathbf{4 , 5 0}$ & $\mathbf{4 , 7 6}$ & $\mathbf{5 , 5 6}$ & $\mathbf{6 , 0 0}$ & $\mathbf{6 , 3 5}$ & $\mathbf{6 , 5 0}$ & $\mathbf{7 , 0 0}$ & $\mathbf{7 , 1 4}$ & $\mathbf{7 , 8 5 9}$ & $\mathbf{7 , 9 4}$ & $\mathbf{8 , 0 0}$ & $\mathbf{8 , 5 0}$ \\
& & & & & & & & & & & & & \\
Medida 1 & 3,10 & 4,45 & 4,55 & 5,55 & 6,00 & 6,33 & 6,55 & 7,10 & 7,13 & 7,86 & 7,89 & 8,10 & 8,54 \\
Medida 2 & 3,18 & 4,48 & 4,68 & 5,62 & 6,02 & 6,31 & 6,57 & 7,08 & 7,13 & 7,86 & 7,99 & 8,07 & 8,65 \\
Medida 3 & 3,20 & 4,37 & 4,59 & 5,55 & 6,08 & 6,34 & 6,60 & 7,09 & 7,22 & 7,85 & 7,95 & 8,09 & 8,67 \\
Medida 4 & 3,19 & 4,23 & 4,75 & 5,54 & 6,00 & 6,34 & 6,51 & 7,03 & 7,16 & 7.85 & 7,93 & 8,02 & 8,54 \\
Medida 5 & 3,00 & 4,50 & 4,76 & 5,56 & 6,00 & 6,35 & 6,50 & 7,00 & 7,14 & 7,86 & 7,94 & 8,00 & 8,50 \\
\hline
\end{tabular}


Para se avaliar a precisão do astigmatismo do sistema, um dispositivo foi desenvolvido para distorcer 3 lentes de contato. Trata-se de uma cunha, presa a um sistema milimétrico de rotação, como mostra a figura 6.2. A deformação na lente é feita pressionando-a no canal da cunha. As lentes foram medidas no ceratômetro Topcon OM-4 (3x cada uma) e no sistema desenvolvido.

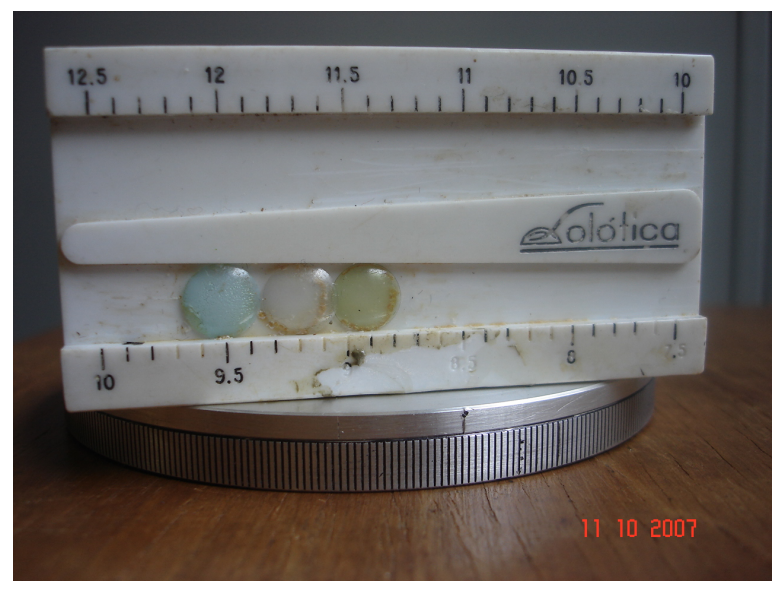

Figura 6.2 Foto do dispositivo em cunha utilizado para deformar as lentes de contato, sobre um sistema que é rotacionado manualmente, a cada $1^{\circ}$.

O dispositivo com cada uma das lentes foi rotacionado nos $360^{\circ} \mathrm{em}$ passos de $1^{0}$.

A Tabela 6.2 mostra as deformações realizadas à $90^{\circ}$ para cada uma delas e o resultado obtido por nosso sistema.

A Tabela 6.3 mostra os dados obtidos, a cada $1^{\circ}$ da lente $A$, no ceratômetro Topcon OM-4 e no nosso sistema, bem como o valor teórico esperado (vide equação 2.1). 
A figura 6.3 mostra o gráfico para a lente $A$ dos valores medidos dos poderes de refração em nosso sistema e no ceratômetro Topcon OM-4, onde cada ponto corresponde à variação de $1^{\circ}$.

A figura 6.4 mostra o gráfico para a lente $A$ dos valores medidos em nosso sistema do ângulo obtido, quando o dispositivo mecânico é rotacionado a cada $1^{\circ}$

O nosso sistema apresentou uma correlação para o poder de refração de $r^{2}=0,95$, para cada $1^{0}$ de rotação da cunha, e o do Topcon OM-4, $r^{2}=0,97$, com relação ao valor teórico. Entre os sistemas a correlação foi de $r^{2}=0,94$ para os poderes de refração e de $r^{2}=0,97$, para o eixo do astigmatismo.

Tabela 6.2: Deformações realizadas à $90^{\circ}$ para três lentes de contato e os resultados obtidos pelo ceratômetroTopcon OM-4 e por nosso sistema.

\begin{tabular}{|c|c|c|}
\hline lente & $\begin{array}{c}\text { Poder de refração } \\
\text { Topcon OM-4 }\end{array}$ & $\begin{array}{c}\text { Poder de refração } \\
\text { Nosso Sistema }\end{array}$ \\
\hline \multirow[t]{2}{*}{ A } & $42,25 \mathrm{D} @ 180^{\circ}$ & $41,75 D @ 180^{\circ}$ \\
\hline & $43,75 D @ 90^{\circ}$ & 43,75D@90 \\
\hline \multirow[t]{2}{*}{ B } & 48,00D @180 & $47,50 \mathrm{D} @ 181^{\circ}$ \\
\hline & 46,25D@90 & $45,55 \mathrm{D} @ 91^{0}$ \\
\hline \multirow[t]{2}{*}{ C } & $48,75 D @ 180^{\circ}$ & 48,25D@179 \\
\hline & $56,25 D @ 90^{\circ}$ & $55,75 D @ 89^{\circ}$ \\
\hline
\end{tabular}


Tabela 6.3: Dados obtidos, a cada $1^{\circ}$ da lente A, no ceratômetro Topcon OM-4 e no nosso sistema, bem como o valor teórico esperado.

\begin{tabular}{|c|c|c|c|c|c|}
\hline \multirow[t]{2}{*}{ Ângulo } & \multirow{2}{*}{$\begin{array}{l}\text { Valor Teórico Esperado } \\
\mathrm{P}=a+b \operatorname{sen}^{2}(\theta-\alpha)\end{array}$} & \multicolumn{2}{|c|}{ Topcon OM-4 } & \multicolumn{2}{|c|}{ Nosso Sistema } \\
\hline & & (D) & graus & (D) & graus \\
\hline 0 & 42,2500 & 41,70 & 0 & 42,62 & 0 \\
\hline 1 & 42,2505 & 41,70 & 1 & 42,62 & 1 \\
\hline 2 & 42,2518 & 41,70 & 2 & 42,62 & 2 \\
\hline 3 & 42,2541 & 41,70 & 3 & 42,63 & 3 \\
\hline 4 & 42,2573 & 41,71 & 4 & 42,63 & 4 \\
\hline 5 & 42,2614 & 41,71 & 5 & 42,63 & 5 \\
\hline 6 & 42,2664 & 41,72 & 6 & 42,64 & 6 \\
\hline 7 & 42,2723 & 41,72 & 7 & 42,64 & 7 \\
\hline 8 & 42,2791 & 41,73 & 8 & 42,65 & 7 \\
\hline 9 & 42,2867 & 41,74 & 8 & 42,66 & 8 \\
\hline 10 & 42,2953 & 41,75 & 9 & 42,67 & 9 \\
\hline 11 & 42,3047 & 41,75 & 11 & 42,68 & 11 \\
\hline 12 & 42,3149 & 41,76 & 12 & 42,69 & 12 \\
\hline 13 & 42,3260 & 41,78 & 13 & 42,70 & 13 \\
\hline 14 & 42,3378 & 41,79 & 14 & 42,71 & 14 \\
\hline 15 & 42,3505 & 41,80 & 15 & 42,72 & 15 \\
\hline 16 & 42,3640 & 41,81 & 16 & 42,74 & 16 \\
\hline 17 & 42,3783 & 41,83 & 17 & 42,75 & 16 \\
\hline 18 & 42,3933 & 41,84 & 18 & 42,77 & 17 \\
\hline 19 & 42,4091 & 41,86 & 19 & 42,78 & 18 \\
\hline 20 & 42,4255 & 41,87 & 20 & 42,80 & 19 \\
\hline 21 & 42,4427 & 41,89 & 21 & 42,82 & 20 \\
\hline 22 & 42,4606 & 41,91 & 22 & 42,83 & 21 \\
\hline 23 & 42,4791 & 41,93 & 22 & 42,85 & 22 \\
\hline 24 & 42,4982 & 41,95 & 23 & 42,87 & 23 \\
\hline
\end{tabular}




\begin{tabular}{|c|c|c|c|c|c|}
\hline 25 & 42,5180 & 41,97 & 24 & 42,89 & 24 \\
\hline 26 & 42,5383 & 41,99 & 25 & 42,91 & 25 \\
\hline 27 & 42,5593 & 42,01 & 26 & 42,93 & 26 \\
\hline 28 & 42,5807 & 42,03 & 26 & 42,96 & 27 \\
\hline 29 & 42,6027 & 42,05 & 28 & 42,98 & 28 \\
\hline 30 & 42,6251 & 42,07 & 29 & 43,00 & 29 \\
\hline 31 & 42,6480 & 42,09 & 29 & 43,02 & 30 \\
\hline 32 & 42,6713 & 42,12 & 30 & 43,05 & 31 \\
\hline 33 & 42,6951 & 42,14 & 31 & 43,07 & 32 \\
\hline 34 & 42,7191 & 42,16 & 33 & 43,10 & 33 \\
\hline 35 & 42,7436 & 42,19 & 34 & 43,12 & 34 \\
\hline 36 & 42,7683 & 42,21 & 35 & 43,14 & 35 \\
\hline 37 & 42,7934 & 42,24 & 36 & 43,17 & 36 \\
\hline 38 & 42,8187 & 42,26 & 37 & 43,20 & 37 \\
\hline 39 & 42,8442 & 42,29 & 38 & 43,22 & 38 \\
\hline 40 & 42,8699 & 42,31 & 39 & 43,25 & 39 \\
\hline 41 & 42,8957 & 42,34 & 40 & 43,27 & 40 \\
\hline 42 & 42,9217 & 42,36 & 41 & 43,30 & 41 \\
\hline 43 & 42,9478 & 42,39 & 42 & 43,33 & 42 \\
\hline 44 & 42,9739 & 42,42 & 43 & 43,35 & 43 \\
\hline 45 & 43,0001 & 42,44 & 44 & 43,38 & 44 \\
\hline 46 & 43,0263 & 42,47 & 45 & 43,40 & 45 \\
\hline 47 & 43,0524 & 42,49 & 46 & 43,43 & 46 \\
\hline 48 & 43,0785 & 42,52 & 47 & 43,46 & 47 \\
\hline 49 & 43,1045 & 42,54 & 48 & 43,48 & 48 \\
\hline 50 & 43,1303 & 42,57 & 49 & 43,51 & 49 \\
\hline 51 & 43,1560 & 42,60 & 50 & 43,54 & 49 \\
\hline 52 & 43,1815 & 42,62 & 51 & 43,56 & 50 \\
\hline 53 & 43,2068 & 42,65 & 52 & 43,59 & 51 \\
\hline 54 & 43,2319 & 42,67 & 53 & 43,61 & 52 \\
\hline
\end{tabular}




\begin{tabular}{|c|c|c|c|c|c|}
\hline 55 & 43,2566 & 42,69 & 54 & 43,64 & 53 \\
\hline 56 & 43,2810 & 42,72 & 55 & 43,66 & 54 \\
\hline 57 & 43,3051 & 42,74 & 56 & 43,69 & 55 \\
\hline 58 & 43,3289 & 42,77 & 57 & 43,71 & 56 \\
\hline 59 & 43,3522 & 42,79 & 58 & 43,73 & 57 \\
\hline 60 & 43,3751 & 42,81 & 59 & 43,76 & 58 \\
\hline 61 & 43,3975 & 42,83 & 60 & 43,78 & 59 \\
\hline 62 & 43,4195 & 42,86 & 61 & 43,80 & 60 \\
\hline 63 & 43,4409 & 42,88 & 62 & 43,82 & 61 \\
\hline 64 & 43,4618 & 42,90 & 63 & 43,84 & 62 \\
\hline 65 & 43,4822 & 42,92 & 64 & 43,86 & 63 \\
\hline 66 & 43,5019 & 42,94 & 65 & 43,88 & 64 \\
\hline 67 & 43,5211 & 42,96 & 66 & 43,90 & 65 \\
\hline 68 & 43,5396 & 42,97 & 67 & 43,92 & 66 \\
\hline 69 & 43,5574 & 42,99 & 68 & 43,94 & 67 \\
\hline 70 & 43,5746 & 43,01 & 69 & 43,96 & 68 \\
\hline 71 & 43,5911 & 43,02 & 70 & 43,97 & 69 \\
\hline 72 & 43,6068 & 43,04 & 71 & 43,99 & 70 \\
\hline 73 & 43,6218 & 43,05 & 72 & 44,01 & 71 \\
\hline 74 & 43,6361 & 43,07 & 73 & 44,02 & 72 \\
\hline 75 & 43,6496 & 43,08 & 74 & 44,03 & 73 \\
\hline 76 & 43,6622 & 43,09 & 74 & 44,05 & 74 \\
\hline 77 & 43,6741 & 43,11 & 75 & 44,06 & 75 \\
\hline 78 & 43,6852 & 43,12 & 76 & 44,07 & 76 \\
\hline 79 & 43,6954 & 43,13 & 77 & 44,08 & 77 \\
\hline 80 & 43,7048 & 43,14 & 78 & 44,09 & 78 \\
\hline 81 & 43,7133 & 43,15 & 79 & 44,10 & 79 \\
\hline 82 & 43,7210 & 43,15 & 80 & 44,11 & 80 \\
\hline 83 & 43,7277 & 43,16 & 81 & 44,11 & 81 \\
\hline 84 & 43,7336 & 43,17 & 82 & 44,12 & 81 \\
\hline
\end{tabular}




\begin{tabular}{llllll}
\hline 85 & 43,7386 & 43,17 & 83 & 44,12 & 82 \\
86 & 43,7427 & 43,17 & 84 & 44,13 & 83 \\
87 & 43,7459 & 43,18 & 85 & 44,13 & 84 \\
88 & 43,7482 & 43,18 & 86 & 44,13 & 85 \\
89 & 43,7495 & 43,18 & 87 & 44,13 & 86 \\
90 & 43,7500 & 43,18 & 88 & 44,13 & 87 \\
\hline
\end{tabular}

O mesmo procedimento foi adotado para as demais lentes ( $\mathrm{B}$ e $\mathrm{C}$ ), e a correlação entre o nosso sistema e o da Topcon OM-4 manteve-se como para a lente $A$.

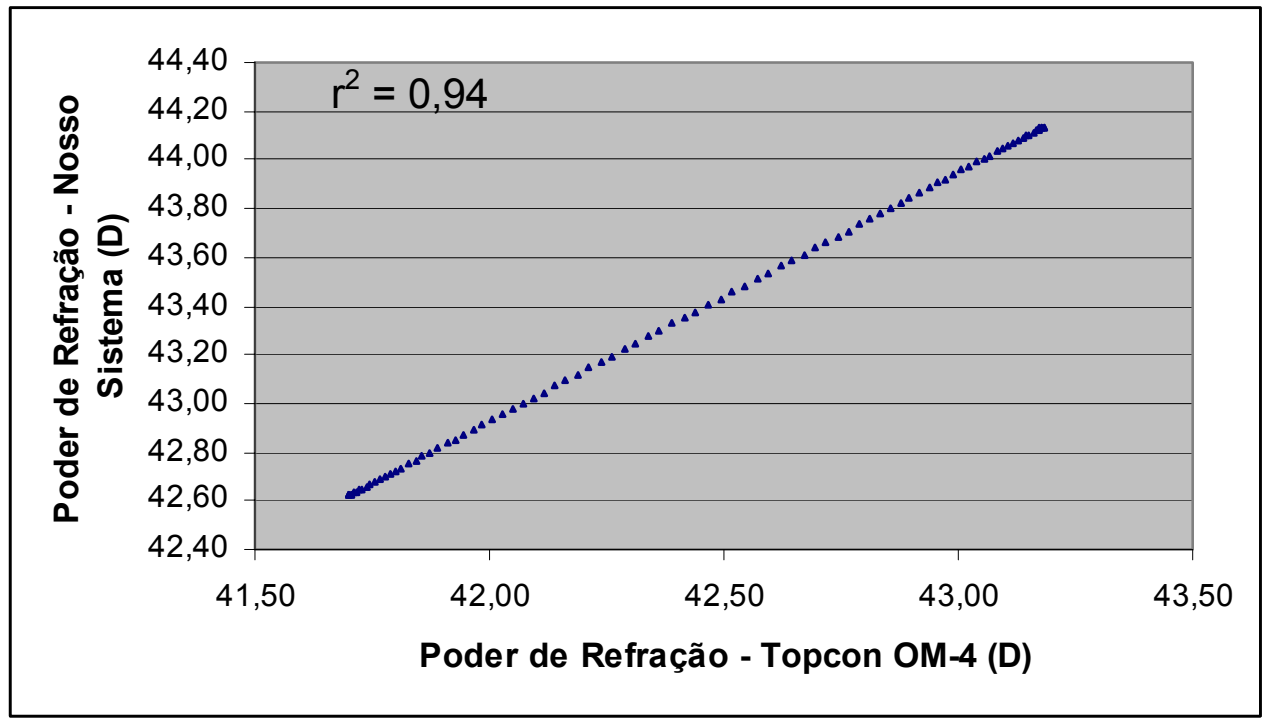

Figura 6.3 Gráfico dos poderes de refração, para a lente A, medidos em nosso sistema e no ceratômetro Topcon OM-4, onde cada ponto corresponde à variação de $1^{\circ}$. 


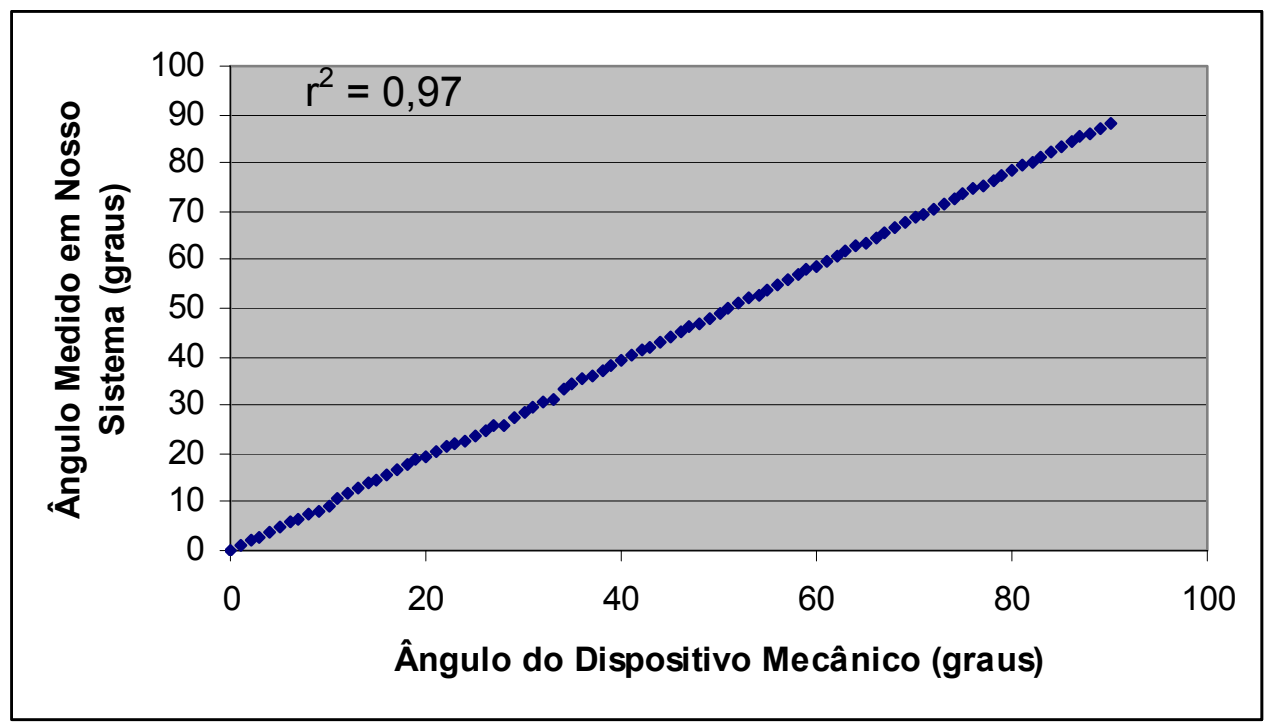

Figura 6.4 Gráfico para a lente A dos valores medidos em nosso sistema do ângulo obtido, quando o dispositivo mecânico é rotacionado a cada $1^{\circ}$.

\subsection{PROFUNDIDADE DE FOCO}

De acordo com a fórmula dos espelhos esféricos, citada anteriormente, e com a calibração do sistema, obtém-se o raio de curvatura da córnea. Nota-se que a precisão desta medida é dependente da distância precisa entre o objeto (a mira de projeção) e a imagem. Bonnet [BONNET, R.; et al; 1962] afirma que "os equipamentos de ceratometria devem possuir uma profundidade de foco inferior a $0,35 \mathrm{~mm}$, para que a precisão no raio de curvatura da superfície medida seja inferior a $0,03 \mathrm{~mm}$ ". Esta é uma exigência bastante restritiva, a qual os ceratômetros comerciais, em sua grande maioria, não cumprem [DEL RIO, G. E.; 1981]. 
Para se medir a profundidade de foco de nosso sistema em microscópio cirúrgico ocular, foram realizadas 60 medidas para a magnificação de 10X, que é a utilizada em ato cirúrgico. A imagem projetada numa esfera foi focalizada e desfocalizada 30 vezes por um mesmo operador e outras 30 vezes por outro operador. A ceratometria era obtida a cada vez que o sistema era focalizado.

Fazendo-se o reverso dos cálculos, utilizando a equação 3.6, ou seja, mantendo-se o raio de curvatura de 7,859mm e a dimensão da mira, através da medida do tamanho da imagem, obtém-se a distância $d$, do objeto (mira) à imagem.

Foi obtida uma profundidade de foco de $0,08 \mathrm{~mm}$, o que levou a uma precisão de 0,5D.

\subsection{AVALIAÇÃO DA MEDIDA DE CIRCULARIDADE}

A função de circularidade tem o objetivo de indicar ao clínico o quanto "circular" está a imagem refletida da córnea sob exame.

Com esta função o cirurgião tem a possibilidade de ajustar as suturas da córnea de modo a deixá-la o mais circular possível em sua região central, onde é feita a projeção da mira luminosa ( $3 \mathrm{~mm}$ de diâmetro para uma córnea com raio de curvatura de $7,859 \mathrm{~mm}$ ). Com isto, o astigmatismo devido à sutura deve ser minimizado. 
Como se pode observar pela figura 5.6, uma circularidade de $98 \%$ já gera um astigmatismo de quase 1D, para raios de curvatura em torno de 7,8mm, que é o de uma córnea padrão.

Assim, para que se possa ter uma idéia do intervalo de circularidade que se pode trabalhar para que um astigmatismo acima de 3D não seja gerado, é necessária a avaliação de muitos olhos. Assim, foram utilizadas as imagens ceratométricas dos 492 olhos avaliados na tese de livre docência da Profa. Dra. Liliane Ventura [VENTURA,L.; 2007], que foram cedidas, para se analisar este item.

Observou-se que para graus de astigmatismo até 3D gerados para raios de curvatura em torno de 7,8mm, uma circularidade mínima de $97 \%$ é necessária. Para córneas mais planas (em torno de 38D), a circularidade mínima é $95 \%$ e para córneas mais curvas (em torno de 55D), a circularidade mínima é $99 \%$.

\subsection{TESTES EM PACIENTES}

Foram realizadas medidas em 14 voluntários em nosso sistema na maca do microscópio cirúrgico ocular e no ceratômetro Topcon OM-4.

A Tabela 6.4 apresenta as medidas dos voluntários em relação ao poder de refração do astigmatismo e ao eixo associado.

A figura 6.5 mostra os gráficos de correlação para o astigmatismo e para o eixo dos dois sistemas comparados. 
O fator de correlação entre o nosso sistema e o Topcon OM-4 para o astigmatismo foi de $r^{2}=0,92$, em relação ao eixo, o fator é $r^{2}=0,99$.

Tabela 6.4: medidas dos voluntários em relação ao poder de refração do astigmatismo e ao eixo associado do nosso sistema comparados ao ceratômetro Topcon OM-4.

\begin{tabular}{lrrrr}
\hline $\begin{array}{c}\text { Volun } \\
\text { tário }\end{array}$ & $\begin{array}{r}\text { Topcon OM-4 } \\
\text { Astigmatismo }\end{array}$ & $\begin{array}{c}\text { Nosso Sistema } \\
\text { Astigmatismo }\end{array}$ & $\begin{array}{c}\text { Nosso } \\
\text { Sistema } \\
\text { Eixo }\end{array}$ & $\begin{array}{c}\text { Topógrafo } \\
\text { Humphrey - } \\
\text { Eixo }\end{array}$ \\
\hline 1 & $-0,75$ & $-0,75$ & 24,00 & 5,00 \\
2 & $-0,50$ & $-0,75$ & 2,00 & 1,00 \\
3 & $-3,00$ & $-2,25$ & 1,00 & 2,00 \\
4 & 0,00 & $-1,50$ & 0,00 & 3,00 \\
6 & $-1,00$ & $-1,25$ & 104,00 & 110,00 \\
7 & $-1,50$ & $-1,75$ & 180,00 & 171,00 \\
8 & $-4,50$ & $-4,75$ & 32,00 & 30,00 \\
9 & $-0,75$ & $-0,50$ & 57,00 & 33,00 \\
10 & $-0,50$ & $-0,50$ & 16,00 & 4,00 \\
11 & $-1,25$ & $-1,00$ & 15,00 & 8,00 \\
12 & $-0,50$ & $-0,75$ & 102,00 & 73,00 \\
13 & $-0,25$ & $-0,75$ & 148,00 & 134,00 \\
14 & $-2,50$ & $-2,75$ & 162,00 & 156,00 \\
\hline
\end{tabular}



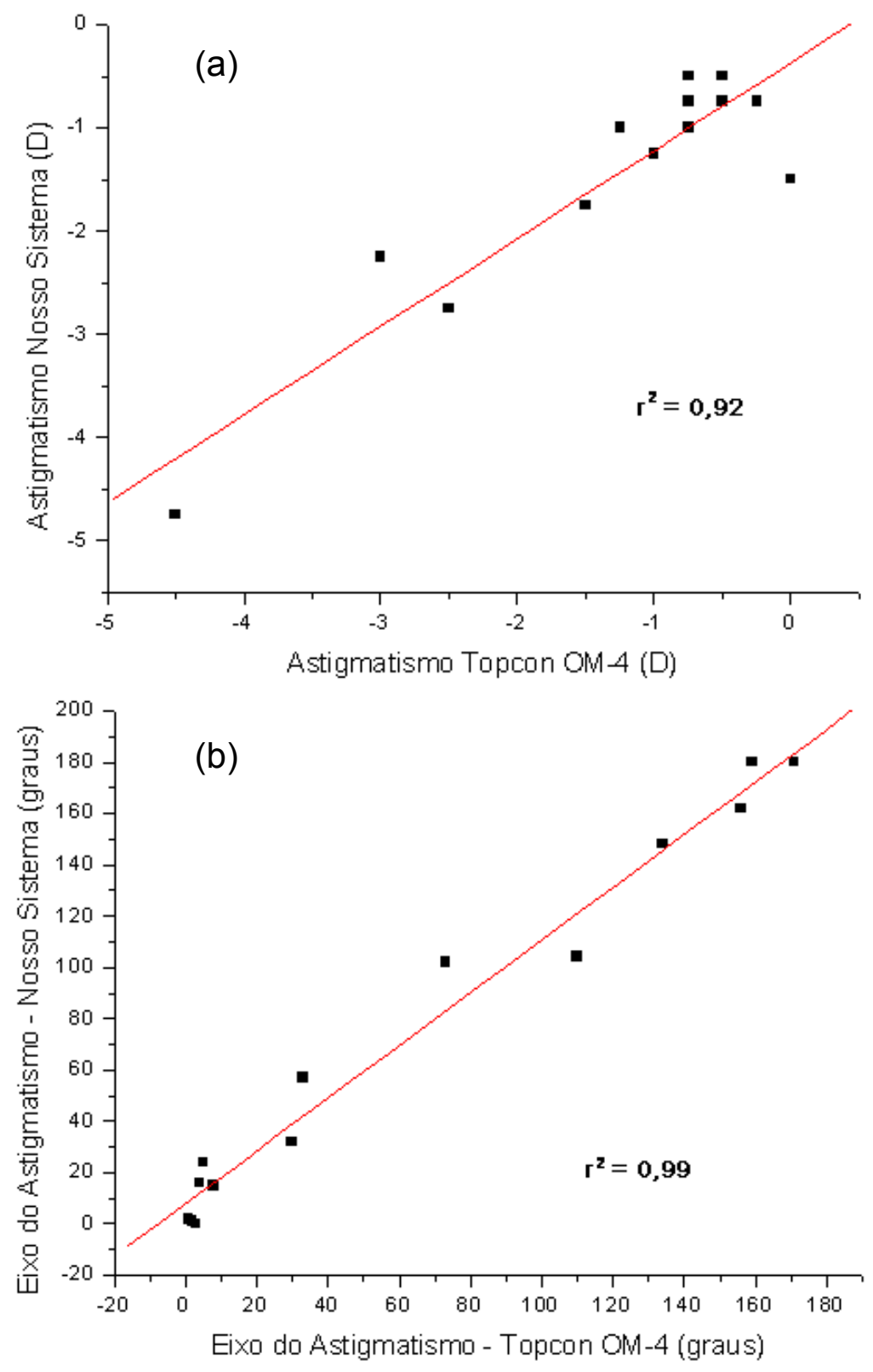

Figura 6.5 Gráficos de correlação dos dois sistemas para o: (a) astigmatismo e; (b) eixo associado. 
Capítulo 7

\section{DISCUSSÕES E CONCLUSÕES}

O sistema de apoio a suturas em cirurgias oculares desenvolvido projeta uma mira de pontos luminosos na córnea do paciente e capta a imagem refletida por esta córnea, que é enviada a um mini computador através do próprio sistema óptico do microscópio cirúrgico ocular (divisor de feixes e adaptador ótico) e pelo sensor CCD (WATEC 221-S) e cabo USB (Pinnacle Linx), com o qual todos os testes foram realizados.

O sistema fornece, através do programa desenvolvido em Delphi 7.0 (da Borland) a ceratometria e a circularidade da córnea durante a sutura.

O reconhecimento da imagem digitalizada de modo a fornecer as informações necessárias à ceratometria e à circularidade é executado pelo programa dedicado ao sistema. O programa determina a distorção da imagem ao ser refletido pelo olho, baseado nas informações da estrutura do alvo. Esta distorção entre a imagem original e a imagem capturada contém os dados que informam as características ceratométricas.

O algoritmo apresentado neste trabalho foi desenvolvido para ceratometria utilizando como alvo um anel discreto formado por fontes luminosas. O algoritmo permite eliminar ruídos externos da imagem, reconstituir a imagem original livre dos defeitos devidos a tais ruídos, reconhecer cada imagem das fontes de luz e, finalmente, determinar as 
características ceratométricas com base nas transformações da imagem original em relação à imagem capturada.

O avanço obtido com as miras atuais compostas por pontos luminosos em relação a anterior foi fundamental para o sucesso da funcionabilidade e precisão obtidas.

O sistema mostrou-se eficiente e preciso o suficiente comparado a equipamentos bem estabelecidos no mercado, como apresentado nos capítulos anteriores.

O intervalo de medida de 32D - 55D é suficiente para estes tipos de exames. O fator de repetibilidade das medidas foi de $90 \%$, mesmo com perturbações luminosas do meio ambiente. A precisão para o raio de curvatura é de $0,05 \mathrm{~mm}$ e para o eixo do astigmatismo é de $2^{\circ}$.

O sistema desenvolvido permite medir meridianos não ortogonais do astigmatismo, uma vez que as informações de todos os raios de curvatura, a cada $1^{\circ}$, estão armazenadas no programa desenvolvido.

Em relação a lentes tóricas, nosso sistema apresentou uma correlação para o poder de refração de $r^{2}=0,95$, para cada $1^{0}$ de rotação da cunha, e o do Topcon OM-4, $\mathrm{r}^{2}=0,97$, com relação ao valor teórico. Entre os sistemas a correlação foi de $r^{2}=0,94$ para os poderes de refração e de $r^{2}=0,97$, para o eixo do astigmatismo, para as lentes tóricas de calibração.

Para 14 pacientes, apesar do número ainda não significativo para se ter uma boa avaliação, foi obtido um fator de correlação entre o nosso sistema e o Topcon OM-4, para o astigmatismo, de $r^{2}=0,92$, e em relação ao eixo, o fator é $r^{2}=0,99$. 
Algumas ceratometrias convencionais foram realizadas em pacientes deitados e sentados para saber se havia alguma diferença nas medidas quando o paciente se encontra em posições diferentes.

O equipamento utilizado, gentilmente emprestado pelo Dr. Erik, foi o Nidek Oculus Hand-held corneal topographer, que é portátil e permite a ceratometria em qualquer posição do paciente.

Três pacientes foram avaliados e os resultados apresentam discrepâncias de valores de até 3D no astigmatismo, porém o eixo se mantém.

Como o número de pacientes avaliados é pequeno, devido à dificuldade em se alinhar o paciente que está deitado, um sistema de apoio e fixação do aparelho será desenvolvido nos próximos meses para que os erros de medidas sejam minimizados (centralização do equipamento principalmente; a focalização é automática) e,então se obter uma medida com confiabilidade.

Como sugestões para aprimoramento do sistema, o anel de LEDs deve ficar fixado ao microscópio ocular, apenas com movimento na vertical para focalização, tornando assim mais fácil seus alinhamento central e angular e sua focalização.

No caso de se optar por usar o sistema de anel de capilares de vidro, que proporciona melhor imagem, um sistema de maior magnificação de imagem deve ser projetado para se obter uma melhor precisão ceratométrica e, portanto, proporcionar melhor avaliação.

A contribuição do presente trabalho foi desenvolver um sistema de apoio a suturas corneanas em cirurgias oculares, de um modo objetivo, proporcionando meios ao cirurgião de minimizar o astigmatismo residual 
induzido pós-operatório, devido à sutura irregular, quanto à circularidade, da córnea.

Espera-se que, uma vez que o sistema passe a ser utilizado, um acompanhamento dos pacientes seja feito para avaliar a contribuição efetiva do sistema no setor cirúrgico ocular. 


\section{REFERÊNCIAS BIBLIOGRÁFICAS}

1. Albert, D.M. Jakobiec, F.A.; editors. Principles and practice of ophthalmology: Basic Sciences. 1st ed. v. 6. Philadelfia: Saunders, 1994.

2. Atchison, A.; Smith, G.; Optics of the Human Eye, Ed. ButterworthHeinemann, 2000.

3. Ballin, N.; Flieringa ring - the poor man's operating keratometer. Ophthalmic. Surg., v. 12, p.443-4, 1981.

4. Barraquer, J. I.; The history of the microscope in ocular surgery. J. Microsurg., v. 1, p.288-99, 1980.

5. Bonnet, R.; Cochet, D. New method of topographical ophthalmometry its theoretical and clinical applications. Am. J. Optom., v. 39, 1962.

6. Colvard, D.M.; Kratz, R.P.; Mazzocco, T.R.; Davidson B.; The Terry surgical keratometer: a 12-month follow-up report. J Am Intraocul Implant Soc. Fall;7(4):348-50. 1981 
7. Cravy, T. V.; Shepard, D. D.; Dynamic keratometry and keratoscopy method and apparatus . US 4165744. Aug, 28, 1979.

8. Cvintal, T.; Complicações do Transplante de Córnea, São Paulo - SP, Editora Santos, p. 482, 2004.

9. Del Rio, G. E.; Queratometria, IN "Óptica Fisiológica Clínica, Refracción” $4^{\mathrm{a}}$ edição, Ediciones Toray, S.A. - Barcelona, p.233-237, 1981.

10. Duke-Elder S,; editor. System of Ophthalmology. - Ophthalmic Optics and Refraction 1st ed. v. V. Londres: Kimpton, 1970.

11. Gormley, D. J.; et al.; "Corneal modeling”, Cornea 7 no.1 (1988), 30-35.

12. Greivenkamp, M.D.; Mellinger, R.W.; Snyder, J.T.; Schwiegerling, A.E.; Lowman, J.; Miller,J.M.; "Comparison of Three Videokeratoscopes in Measurement of Toric Test Surfaces," J. Ref. Surg. 12 229-239 1996.

13. Hecht, E.; Optics New York, Addison-Wesley Publishing Company, Second Edition, 1990.

14. Igarashi, H.; Akiba, J.; Hirokawa, H. ; Yoshida, A. Measurement of the 
radius of corneal curvature with the Maloney surgical keratometer. Am. J. Ophthalmol., v. 112, p.211-2, 1991.

15. Jongsma, F.H.M.; De Brabander, J.; Hendrikse, F.; Review and Classification of Corneal Topographers, Lasers Med Sci, 14:2-19, 1999.

16. Jongsma, F.H.M.; De Brabander, J.; Hendrikse, F.; Review and Classification of Corneal Topographers, Lasers Med Sci, 14:2-19, 1999.

17. Jue, B; and Maurice, D.M.; "The Mechanical Properties of the Rabbit and Human Cornea", J. Biomechanics, vol. 19, n. 10, pp. 847-853, 1986.

18. Mandell, R.; Jesse Ramsden: Inventor of the Ophthalmometer. Am. J. Optom., v. 37, p.633-38, 1960.

19. Manning CA, Kloess PM; Comparison of portable automated keratometry and manual keratometry for IOL calculation, J Cataract Refract Surg. 1997 Oct;23(8):1213-6.

20. Mesaros, J.; G.; Mocilac, J.P.; Terry;, C.M.; Keratometric device , USPatent 4429960, February 7, 1984. 
21. Mocilac, J. P.; Terry, C. ; Mesaros, J. G. Keratometric device . US 4429960. Feb. 7, 1984.

22. Mohrman, R.; "The Keratometer", In: Clinical Ophthalmology, Ed.: T. D. Duane, Philadelphia: J. B. Lippincott Company, cap. 60, pp. 1-12, 1981.

23. Polisuk, P. Topografia da Córnea: Atlas Clínico. Cultura Médica, 2004, 255p., 2003.

24. Prado, D.; De Wollaston a Javal. Arq. Bras. Oftal., v. 4, p.342-48, 1941.

25. Saia, P.; Monografia de Qualificação de Mestrado: Desenvolvimento de um Sistema Portátil de Ceratometria, Escola de Engenharia de São Carlos - USP, Agosto de 2007.

26. Schor, P.; Tese de Doutorado: Idealização, Desenho, Construção e Teste de um Ceratômetro Cirúrgico Quantitativo, UNIFESP, São Paulo, 1997.

27. Spalton, D.J.; Hitchings, R.A.; Hunter, P.A.; Tan, J.C.H; , Harry, J.; Atlas of Clinical Ophthalmology, Chapter 6, p.148, Ed. Elselvier Mosby, USA, 2005. 
28. Steinbruch, A.; Winterle, P.; Geometria Analítica -2. ${ }^{a}$ edição - São Paulo, McGraw-Hill, 1987.

29. Tate, G. J.; Safir, A.; Mills, C.; Bowling, J.; Mc Donald, J. ; Craig, M. Accuracy and reproducibility of keratometer readings. C.L.A.O. J., v. 13, p.50-8, 1987.

30. Troutman, R. C.; RUSSA, J. A. L. ; Surgical Microsystems, Inc. Indicating an asphericity of the cornea of an eye - US 4046463. Sept. 6, 1977.

31. Troutman, R.; Surgical keratometer in the management of astigmatism in keratoplasty. Ann. Ophthalmol., v. 19, p.473-4, 1987.

32. Troutman, R.; Kelly, S.; Kaye, D. ; Clahane, A.; The use and preliminary results of the Troutman surgical keratometer in cataract and corneal surgery. Trans. Am. Acad. Ophthalmol. Otolaryngol., v. 83, p.232-8, 1977.

33. Ventura, L.; Castro, J.C. - Ametropias Oculares - Rev. Bras. Ens. Fís., V. 17, n.4, p. 01-12, Dez. 1995. 
34. Ventura, L,; De Groote, J-J.; Faria e Sousa, S.J.; patente nacional: Módulo Ceratométrico Para Acoplamento Em Lâmpada De Fenda E Ou Microscópicos Oculares, PI 0305483-7, 07/07/2003.

35. Ventura, L,; De Groote, J-J.; Faria e Sousa, S.J.; patente internacional: Keratometric Module For Coupling To Slit Lamps And Ocular Microscopes, WO 2005/002427 A1, Natureza: INVENÇÃO, 13/01/2005.

36. Ventura, L.; Riul, C.; Sousa, S.J.F.;De Groote, J.G.S.; Rosa, A.B.; Oliveira, G.C.D.; Corneal astigmatism measuring module for slit lamps Phys. Med. Biol. 51 p. 1-14 (2006).

37. Ventura, L.; Tese de Livre-Docência em Engenharia Elétrica, Módulo Ceratométrico para Microscópios Oculares; Área: Instrumentação e Imagens em Oftalmologia; Escola de Engenharia de São Carlos - USP, Julho de 2007.

38. Whitson, W.E.; Weisenthal, R.W.; Krachmer, J.H.; Penetrating Keratoplasty and Keratoprosthesis. IN: Duane, T.D. Philadelphia: J. B. Lippincott Company, cap. 26, pp. 1-27, 1994. 